\title{
Vertical Line Extension Decisions in a Competitive Market with Consumers' Need for Product Uniqueness
}

\author{
Jie Wang $\mathbb{D},{ }^{1}$ Qin Su $\mathbb{D},{ }^{1}$ and Canyou Wang $\mathbb{D}^{2}$ \\ ${ }^{1}$ School of Management, Xi'an Jiaotong University, Xi'an 710049, China \\ ${ }^{2}$ School of Public Administration and Law, Chang'an University, Xi'an 710064, China \\ Correspondence should be addressed to Jie Wang; 19881206wj@163.com
}

Received 8 May 2020; Revised 27 August 2020; Accepted 31 October 2020; Published 24 November 2020

Academic Editor: Daniele Fournier Prunaret

Copyright (c) 2020 Jie Wang et al. This is an open access article distributed under the Creative Commons Attribution License, which permits unrestricted use, distribution, and reproduction in any medium, provided the original work is properly cited.

One important reason for offering customized products is to satisfy consumers' need for product uniqueness. In this paper, we take consumers' unique preferences into account to examine how firms make decisions on vertical line extensions with introducing a customized product. This study develops the consumer's utility function, which captures consumers' behavioural and emotional factors, and the results show that the high-quality firm always introduces an upward extension without uniqueness sensitivity. However, introducing a downward extension may be more profitable especially when consumers have the high unique ness sensitivity. We also find that the upward extension of the high-quality firm does not intensify competition with the low-quality firm, but its downward extension will intensify the competition between two firms, whether with or without unique preferences. We also analyse the low-quality firm's extension decisions when it faces a high-end competitor and find that the lowquality firm may change from introducing a downward extension to introducing an upward extension when intrafirm quality differentiation is small.

\section{Introduction}

With the help of flexible manufacturing and process technologies, the power of the Internet, many firms have increasingly utilized customization strategies to produce customized products to attract more consumers with the high self-consciousness [1-3]. For example, consumers can work with Lenovo Imaging Technology Center to customize each setting of their PCs such as changing the boot order of devices. Nike also provides customization service which shoppers can make part of their own shoes with access to printing, embroidery, lasering, accessory bar, and more. Consumers' need for uniqueness is defined as an individual's pursuit of differentness relative to others that is achieved through the acquisition, utilization, and disposition of consumer goods for the purpose of developing and enhancing one's personal and social identity [4]. And, it becomes an important driver for purchasing products.

One important question marketing and manufacturing managers must consider is how to introduce vertical line extensions for meeting diversified demands. Manufacturers often design vertical line by increasing quality differentiation to relieve cannibalization and competition [5-7]. Firms selling multiple quality-differentiated products frequently alter their quality setting and sequence when facing different competitors $[8,9]$. The traditional approach emphasizes expanding the differences of products to meet consumers who have heterogeneity on product quality, while it ignores other attributes of products. In fact, not only the intrinsic value of products but also the consumption externality affects the consumers' purchasing decisions. This paper builds on past literature and contributes to it by showing that firms may make the opposite decisions on vertical line extensions by introducing a customized product and diluting quality differentiation. In fact, increasing product differences in multiple dimensions can relieve the pressure on a quality upgrade in vertical line extensions.

Concurrently, a growing number of emerging studies have addressed issues involved in offering a customized product [10-12]. Scholars have shown that offering a 
customizable product is an independent strategy in a monopoly market [13] and a competitive market, rather than in the context of vertical line extensions. Additionally and importantly, the consumer behavioural or emotional factors that influence purchase decision-making have yet to be adequately explored in these studies [14, 15]. Another limitation associated with the literature focusing on vertical line extensions lies in the trade-off between quality differentiation and price discrimination, while ignoring the demand side of consumer needs and preferences for different dimensions of products.

Given the importance of customization industry, examining the impact of consumers' unique preferences on vertical line extensions is quite necessary for a large number of managers. First, firms should take consumers' unique preferences into account when they intend to introduce a customized product. Because introducing a new type of product in the vertical line influences consumers' value perception and preferences' tendency. Second, considering the exclusivity-seeking consumers, prior research on vertical line extensions may not apply. Consumers' unique preferences do affect their purchase decisions, which in turn influence firms' vertical line extension decisions and profits. Therefore, the central question addressed in this paper is how firms introducing a customized product make vertical line extension decisions when they take consumers' unique preferences into account. Specifically, we address the following questions:

(1) How do firms position their customized product, that is, decide whether to extend upwards or downwards?

(2) How do uniqueness sensitivity and quality differentiation influence firms' profit equilibria?

(2) How do firms' vertical line extension decisions affect their competitive relationships?

To answer these questions, we develop a game model of a high-quality firm and a low-quality firm making decisions on product line extensions which introduce the customization technology to meet customers' need for uniqueness. We develop the consumer's utility function, which captures consumers' valuation for quality and uniqueness. We consider two scenarios: an upward extension scenario and a downward extension scenario. Based on our model, we obtain several key insights. First, introducing a downward extension may drive the high-quality firm to get more profit when considering consumers' unique preferences, which is different from the results of the high-quality firms which are always introduce upward extensions [16, 17]. Second, the high-quality firm is more aggressive towards the low-quality firm when introducing a downward extension. Third, we determine the impacts of the quality differentiation of customized products and base products on the firms' vertical line extensions.

This paper builds on the past literature on product line design and contributes to it in several points. First, conventional wisdom might claim that firms always expand vertical differentiation $[6,18]$, and high-end firms tend to introduce upward extensions [16, 17]. This result holds in our model if consumers do not exhibit unique preferences. However, this paper provides interesting insight that the high-quality firm can obtain a higher profit by introducing a downward extension if consumers do exhibit unique preferences. This is because unique preferences increase the differentiation between base products and customized products, which alleviates intrafirm cannibalization and pressure on quality upgrade. Second, by emphasizing the behavioural and emotional factors, we incorporate the uniqueness sensitivity into the analysis of optimal equilibrium and examine that the demands and prices of the highquality firm increase with consumers' unique preferences, leading to a wider range of situations of introducing a downward extension rather than an upward extension. Third, the high-quality firm introducing an upward extension does not affect the low-quality firm's profit with or without unique preferences. However, a downward extension of the high-quality firm erodes the low-quality firm's profit, especially the increase of intrafirm quality differentiation.

The outline of this paper is organized as follows. In Section 2, we report our contributions but start with reviewing related literature. In Section 3, we present our basic modelling framework in detail. In Section 4, we examine the high-quality firm's decisions on vertical line extensions when considering consumers' unique preferences and determine the conditions of different extension strategies. In Section 5, we perform a comparative analysis of the low-quality firm on how to expend vertical line and relax the assumptions to verify the robustness of the conclusions. In Section 6, we conclude and discuss the implications and limitations of this paper. All of the proofs are provided in the Appendix.

\section{Literature Review}

This paper is closely related to three streams of literature. First, our research builds on the existing literature on product line design. With a focus on vertical differentiation, traditional studies assume the firm offering a series of products of the same generic type to satisfy different tastes and preferences and use a price-quality schedule to target consumer segments [19]. Moorthy [20] ensures lowerquality products potentially cannibalize higher-quality products and the firm sets less quality for the low-valuation segment to relieve the cannibalization effect. In [21], a sequential product introduction strategy can alleviate cannibalization by introducing a high-end product before a lowend product. Desai [18] finds that introducing downward extensions can drive consumers to migrate to low-end products and cause cannibalization. Biyalogorsky and Koenigsberg [22] show that simultaneous introduction should be used when the level of demand uncertainty is low. Bhattacharya et al. [23] reveal that improvements in technology delay the introduction of a high-end product and benefit of launching the low-end product earlier offsets the loss of cannibalization. However, these research studies all assume products with different qualities are the same generic 
type, ignoring different types of products. Unlike these studies, we examine how consumers' demand attributes affect firms' profits when they introduce customized products.

Second, our paper is related to the literature on social psychology that identifies the existence of exclusivityseeking consumer behaviour and examines how these behaviours impact firms' decisions. In this field, some researchers have focused on consumers' unique preferences leading to exclusive consumption. Cheema and Kaikati [24] examine the psychosocial cost associated with positive word of mouth, which can decrease the uniqueness of possessions and harm high unique consumers. Amaldoss and Jain $[25,26]$ introduce a framework with exclusivity-seeking and conformity-seeking consumers and analyse the effect of conspicuous consumption on consumer demand. Agrawal et al. [27] show that price and demand for conspicuous goods may be observed to jointly increase due to firms' durability choice. Rao and Schaefer [28] construct a dynamic model to examine purchase behaviour and firm strategy affected by status utility. However, the formal modelling literature is somewhat limited in the area of exclusive consumption. Many studies fail to take quality's effect on consumer preferences into account and focuses solely on social benefits. In addition, they do not consider that the popularity of customization technology highlights the exclusivity of products, whether durable or nondurable products. Accordingly, we jointly consider intrinsic quality and uniqueness utility to describe the multiple characteristics of exclusive consumption.

Finally, this study is also related to a significant body of literature on product customization. Most of the literature on customization is based on the horizontal differentiation model to explore the product-type strategies. Xia and Rajagopalan [29] construct a game-theoretic duopoly model to study the standardization and customization decisions of two firms along with variety, lead time, and price decisions. Alptekinoğlu and Corbett [30] study the competition between a mass customizer and a mass producer. Their results show that even if the mass producer has a small cost disadvantage, it can survive the intense competition. Syam and Kumar $[10,11]$ explore the appropriate level of customization in a duopoly setting and find that when firms offer custom products and standard products, they tend to offer partial rather than full customization to reduce price competition. The existing scholarship in this field has tended to focus on a monopolistic setting to examine the effect of customization on the firms' product line decisions. Gu and Tayi [13] investigate a monopolistic firm's strategies in offering a standard product, a consumer customizable product, or both. They found that the firm would offer a consumer customizable product only if the customizing capability is sufficiently high. Basu and Bhaskaran [31] develop analytical models to investigate how the consumer customization strategy affects firms' product line designs and quality of products. Our study differs from these studies in the following aspects. First, we incorporate consumers' uniqueness sensitivity into the analysis of optimal equilibrium in a duopoly by emphasizing the role of behavioural and emotional factors. Second, we introduce a framework with a high-quality firm and a low-quality firm in a competitive market and examine how demand attributes (consumers' need for product quality and uniqueness) affect firms' profits and vertical line extensions. Finally, we capture vertical differentiation of quality and horizontal differentiation of product type to verify which vertical line extension strategy is more appropriate to introduce customization technology.

\section{The Basic Model}

3.1. Firms. Consider a duopoly where firm $i(i=1,2)$ offers a base product. In the tradition of the literature on vertical differentiation, we refer to firm 1 as the high-quality firm offering a higher-quality product $q_{1 b}$ at price $p_{1 b}$ and firm 2 as the low-quality firm offering a low-quality product $q_{2}$ at price $p_{2}$. The high-quality firm wants to stretch its product line by introducing a customized product to satisfy customers' need for uniqueness. Hence, it faces two choices: either to introduce an upward extension (denoted as $U$ strategy) whose quality is $q_{1 h}>q_{1 b}$ or a downward extension (denoted as $S$ strategy) whose quality is $q_{1 l}<q_{1 b}$. Without loss of generality, we assume that $q_{1 h}-q_{1 b}=q_{1 b}-q_{1 l}=\mu$, where $\mu$ is the quality differentiation between firm 1's base product and extensions. Note that, to facilitate the theoretical analysis, we assume that the quality differentiation between firm 1's base product and upward extension is the same as the quality differentiation between its base product and downward extension.

Now consider firm 2, which competes with firm 1 in the market with a base product whose quality is $q_{2}$. We consider situations that firm 1 focuses on the high-end market, and firm 2 is positioned at the low-end market. In Section 5, we examine the situation in which firm 2 wants to expand product line. Following Li [32], let $q_{1 b}-q_{2}=m$, where $m$ indicates the quality differentiation between the two firms' base products. To ensure that firm 1's product quality is higher than firm 2's, the quality of firm 1's downward extension needs to be higher than firm 2' quality (i.e., $q_{1 l}>q_{2}$ ). We standardize the interfirm quality differentiation to unity (i.e., $m=1$ ), and this assumption implies that the intrafirm quality differentiation is less than unity (i.e., $\mu<1$ ).

The marginal cost of producing a product depends on its quality level, and we assume $c\left(q_{i}\right)=\left(q_{i}^{2} / 2\right)$ (see Moorthy [20] and Desai [6], for a similar assumption). So, we let that firm 2's marginal cost for a base product is $c_{2}=\left(q_{2}^{2} / 2\right)$, and firm 1's marginal cost for products are $c_{1 l}=$ $\left(\left(q_{2}+1-\mu\right)^{2} / 2\right), \quad c_{1 b}=\left(\left(q_{2}+1\right)^{2} / 2\right), \quad$ and $\quad c_{1 h}=\left(\left(q_{2}+\right.\right.$ $1+\mu)^{2} / 2$ ). To simplify analysis, we standardize firm 2 's marginal cost to zero, that is, $q_{2}=0$ [33]. In Section 5, we relax these assumptions to consider a generalized cost function. In the main model, we assume that the cost functions take a specific form to simplify analysis and focus on the impact of demand-side mechanisms on vertical line extensions. We normalize firms' customization cost to zero without loss of generality and extend our model to consider customization cost in Section 5.3. 
3.2. Consumers. Consider that the market is comprised of two types of consumers with and without unique preferences. We capture consumers' desire for uniqueness by allowing the utility derived from the customized product to depend not only on its intrinsic value but also on the consumption externality.

3.2.1. Basic Utility. We refer to the utilitarian value that consumers receive from the base product as the basic utility. We consider a fully served market in which consumers have heterogeneous valuation for quality. $v$ is the consumer's reservation utility for the base product. We assume that $v$ is sufficiently high so that all consumers buy the product and the market is fully served [29]. To depict the situation of two competitive firms, we normalize market size to one and assume that quality valuation $\theta$ is uniformly distributed over the interval $[0,1]$ (in vertical product differentiation model, ? represents the consumer's willingness to pay for quality and varies across consumers. Each consumer is a surplus maximizer and desires at most one unit of the product. However, the hotelling model has always been used to characterize the price-dependent demand in the case of two or more competing firms. Therefore, we use quality-dependent model to analyse firms' decisions on vertical line extensions). Consequently, the utility derived by a consumer from purchasing a base product from firm $i$ with quality $q_{o}$ and price $p_{o}$ is given by

$$
U\left(p_{o}, q_{o} ; \theta_{i}\right)=v+\theta_{i} q_{o}-p_{o}, \quad \theta_{i} \in[0,1], o \varepsilon\{2,1 h, 1 b, 1 l\} .
$$

3.2.2. Uniqueness Utility. We develop the uniqueness utility function, which captures the behavioural and emotional factors and highlights the exclusivity of customized products. Franke and Schreier $[34,35]$ find that, in addition to the significant effect of aesthetic and functional fit, the perceived uniqueness of a customized product (1) contributes independently to the utility a customer experience and (2) that this effect is moderated by the consumers' need for uniqueness. In other words, product uniqueness as a value driver in customized product facilitates enhanced differentiation from other consumers and their belongings by means of a truly unique product. In the motivation of social identity, customized product can achieve some kind of social interaction and convey the identification information, enabling relevant consumer groups to accurately infer their unique taste, so as to obtain social recognition. This explains why consumers tend to customize some public products (e.g., T-shirts, sneakers, bicycles, and graduation shirts) over nonpublic products (e.g., soaps, toothpaste, and sofas).

Following Amaldoss and Jain [25, 26], they model snobs as consumers whose utility from a product decreases as more people consume the same product. For example, a BMW in every driveway could dilute the value of the car to potential buyers. Therefore, the more the consumers buy base products, the higher the uniqueness value of consumers who buy customized products is. Following the ideas of Li [32], Rao and Schaefer [28], Gao et al. [36] on the construction of social status utility for buyers, they assume that consumers have homogeneous status preferences, as the higher-status consumers buy a product, and the product's status utility becomes higher. Based on the construction of social status utility for buyers, we try to introduce the construction concept into the depiction of consumers' unique preferences for customized products. Consumers who purchase the customized product derive utility from two different factors: quality and uniqueness. So, if one consumer buys a customized product, he gets utility:

$$
\begin{aligned}
U\left(p_{o}, q_{o} ; \theta_{i}\right) & =v+\theta_{i} q_{o}-p_{o}+\tau Q_{N}, \\
\theta_{i} & \in[0,1], \text { os }\{2,1 h, 1 b, 1 l\},
\end{aligned}
$$

where the parameter $Q_{N}$ represents the number of consumers who purchase the base product and $\tau$ represents the consumers' sensitivity to uniqueness (we use the term "sensitivity to uniqueness" to describe $\tau$. Our assumption about uniqueness utility implies that the consumer's willingness to pay for the customized product is influenced by internal sensitivity $\tau$ and external group $Q_{N}$. This approach allows us to gain the same insights as a more complex model such as the Hotelling model. Furthermore, our model is also general enough to accommodate contexts where firms' decisions on vertical line extensions are motivated by the demand attributes (consumers' need for product quality and uniqueness)). Suppose that consumers located in the range of $\left[\theta_{l}, \theta_{h}\right]$, $\left(0<\theta_{l}<\theta_{h}<1\right)$ buy the customized product, and the number of consumers who buy a base product is $Q_{N}=1-\left(\theta_{h}-\theta_{l}\right)$. The formulation reflects the notion that one consumer has the special need to be different from others and separates himself from the masses by representing the awareness of uniqueness. A consumer enjoys a positive benefit $\tau$ if no other consumer owns the customized product $\left(\theta_{h}-\theta_{l}=0\right)$, and there is no benefit due to the exclusivity if all consumers own the customized product $\left(Q_{N}=0\right)$.

This formulation of uniqueness utility captures two key characteristics of conspicuous consumption of customized products. First, the uniqueness value of customized products increases with the number of consumers buying the base products, that is, decreases with the number of consumers buying the customized products. It is because that the consumers seeking uniqueness show great exclusivity. For instance, the strategies of customization and limiting production quantity are practiced in many categories such as cars, watches, and jewelry. Second, the uniqueness value of customized products is determined by the consumers' sensitivity to uniqueness. Consider the case that consumers have the need for uniqueness to separate themselves from others, but they have different sensitivities to different products. For example, consumers have the higher uniqueness sensitivity to customized T-shirt than soup.

\section{Analysis and Results}

4.1. Consumers without Uniqueness Preferences. Considering consumers do not have unique preferences $(\tau=0)$, we first analyse the product line extension strategies of the high-quality firm. 
Case 1 (high-quality firm with no extensions ( $N$ strategy)). Suppose that the consumer with $\bar{\theta}$ is indifferent between buying firm 1's base product and firm 2's base product, where $\left(v+\bar{\theta} q_{1 b}-p_{1 b}=v+\bar{\theta} q_{2}-p_{2}\right)$. Solving this equation for $\bar{\theta}$, we obtain $\bar{\theta}=\left(p_{1 b}-p_{2} / q_{1 b}-q_{2}\right)=p_{1 b}-p_{2}$. In this case, the two firms' profits are expressed as follows:

$$
\left\{\begin{array}{l}
\pi_{1}=(1-\bar{\theta})\left(p_{1 b}-c_{1 b}\right) \\
\pi_{2}=(\bar{\theta})\left(p_{2}-c_{2}\right)
\end{array}\right.
$$

Using the first-order conditions, the equilibrium prices for firms 1 and 2, respectively, are $p_{1 b}^{N}=1$ and $p_{2}^{N}=(1 / 2)$, the equilibrium demands are $d_{1 b}^{N}=d_{2}^{N}=(1 / 2)$, and optimal profits are $\pi_{1}^{N}=\pi_{2}^{N}=(1 / 4)$.

Case 2 (high-quality firm with an upward extension ( $U$ strategy)). When firm 1 introduces a high-quality customized product, three products with qualities $q_{1 h}>q_{1 b}>q_{2}$ are offered. Consequently, there are two indifferent consumers prevalent in the market. One of them is indifferent between firm 1's base product and firm 2's base product $\left(v+\theta_{1} q_{2}-p_{2}=v+\theta_{1} q_{1 b}-p_{1 b}\right)$. The income parameter of this consumer is given by $\theta_{1}^{U}=\left(p_{1 b}{ }^{-}\right.$ $\left.p_{2} / q_{1 b}-q_{2}\right)=p_{1 b}-p_{2}$. Another consumer who is indifferent between firm 1's base product with quality $q_{1 b}$ and customized product with quality $q_{1 h}\left(v+\theta_{2} q_{1 b}-p_{1 b}=v+\right.$ $\left.\theta_{2} q_{1 h}-p_{1 h}\right)$ is represented by $\theta_{2}^{U}=\left(p_{1 h}-p_{1 b} / \mu\right)$. Similarly, the optimal profits of the two firms are expressed as follows:

$$
\text { U Stategy : }\left\{\begin{array}{l}
\pi_{1}^{U}=\frac{\mu^{3}+4}{16}, \\
\pi_{2}^{U}=\frac{1}{4} .
\end{array}\right.
$$

Case 3 (high-quality firm with a downward extension ( $D$ strategy)). When firm 1 introduces a low-quality customized product, three products with qualities $\left(q_{1 b}>q_{1 l}>q_{2}\right)$ are offered. The consumer who is indifferent between buying firm 2's base product and firm 1's customized product with quality $q_{1 l}\left(v+\theta_{1} q_{2}-p_{2}=v+\theta_{1} q_{1 l}-p_{1 l}\right)$ is represented by $\theta_{1}^{D}=\left(p_{1 l}-p_{2} / 1-\mu\right)$. The consumer who is indifferent between buying firm 1's customized product with quality $q_{1 l}$ and base product with quality $q_{1 b}\left(v+\theta_{2} q_{1 b}-p_{1 b}=v+\theta_{2} q_{1 l}-p_{1 l}\right)$ is represented by $\theta_{2}^{D}=\left(p_{1 b}-p_{1 l} / \mu\right)$. follows:

The optimal profits of the two firms are expressed as

$$
\text { DStrategy : }\left\{\begin{array}{l}
\pi_{1}^{D}=\frac{5 \mu^{3}-20 \mu^{2}-12 \mu+36}{144}, \\
\pi_{2}^{D}=\frac{(1-\mu)(3-\mu)^{2}}{36} .
\end{array}\right.
$$

Lemma 1. Without unique preferences, the high-quality firm always introduces an upward extension ( $U$ strategy), and this strategy does not influence the low-quality firm's profit.
Lemma 1 illustrates that the high-quality firm always chooses $U$ strategy if the consumers do not have unique preferences for a customized product. Under this condition, it does not intensify the price competition between the two firms $\left(p_{1 b}^{U}=1, p_{1 h}^{U}=\left(\mu^{2} / 4\right)+\mu+1\right.$, and $\left.p_{2}^{U}=(1 / 2)\right)$. Because of this relationship, the two firms do not cannibalize each other's market share $\bar{\theta}=(1 / 2)$. The highquality firm provides two kinds of products for consumers when introducing product line extensions and further extracts consumer surplus to drive more profits through price discrimination. Under this situation, the price and demand of the low-quality firm have not been compressed, so its profit has not been hurt.

However, if the high-quality firm introduces a downward extension, as the differentiation between the highquality firm's downward extension $\left(q_{1 l}\right)$ and the low-quality firm's base product $\left(q_{2}\right)$ declines, competition between two firms becomes more intense. First, prices of competing products all declines $\left(p_{1 l}^{D}=\left(\mu^{2} / 3\right)-((4 \mu) / 3)+1<p_{1 b}^{N}=1\right)$ and $\left.p_{2}^{D}=\left(\mu^{2} / 6\right)-((2 \mu) / 3)+(1 / 2)<p_{2}^{N}=(1 / 2)\right)$. Second, consumers who would buy the low-quality firm's base product switch to the high-quality firm's downward extension because of the price reduction $\left(p_{1 l}^{D}<1\right)$. Therefore, the demand for the high-quality firm's base product declines, in turn causes its price to fall $p_{1 \mathrm{~b}}^{D}=\left(\mu^{2} / 12\right)-(\mu / 3)+1<p_{1 b}^{N}=1$. As a result, the downward extension strategy increases the intrafirm cannibalization. In short, the internal cannibalization effect and external competition effect together reduce the profit of the high-quality firm. The profit and market share of the lowquality firm all decline because of external intensifying competition. So, if the high-quality firm introduces a downward extension, it would create a lose-lose situation for both sides.

4.2. Consumers with Uniqueness Preferences. Suppose that consumers have unique preferences, how does the highquality firm expand product line through introducing customization technology?

4.2.1. Upward Extension. When the high-quality firm introduces a high-quality customized product, three products with qualities $q_{1 h}>q_{1 b}>q_{2}$ are offered. Consequently, there are two indifferent consumers prevalent in the market. One of them is indifferent between buying the low-quality firm's product with quality $q_{2}$ and the high-quality firm's base product with quality $q_{1 b}\left(v+\theta_{1} q_{2}-p_{2}=v+\theta_{1} q_{1 b}-p_{1 b}\right)$. The income parameter of this consumer is given by $\theta_{1}^{U *}=\left(p_{1 b}-p_{2} / q_{1 b}-q_{2}\right)=p_{1 b}-p_{2}$. Another consumer who is indifferent between the high-quality firm's base product with quality $q_{1 b}$ and customized product with quality $q_{1 h}\left(v+\theta_{2} q_{1 b}-p_{1 b}=v+\theta_{2} q_{1 h}-p_{1 h}+\tau \theta_{2}\right)$ is represented by $\theta_{2}^{U *}=\left(p_{1 h}-p_{1 b} / q_{1 h}-q_{1 b}+\tau\right)=$ $\left(p_{1 h}-p_{1 b} / \mu+\tau\right)$. For the profit functions, we obtain

$$
\left\{\begin{array}{l}
\pi_{1}=\left(\theta_{2}-\theta_{1}\right)\left(p_{1 b}-c_{1 b}\right)+\left(1-\theta_{2}\right)\left(p_{1 h}-c_{1 h}\right), \\
\pi_{2}=\left(\theta_{1}\right)\left(p_{2}-c_{2}\right) .
\end{array}\right.
$$


The first-order condition of this problem $\left(p_{1 h}, p_{1 b}\right.$, and $\left.p_{2}\right)$ yields the corresponding prices: $p_{2}^{U *}=(1 / 2), p_{1 b}^{U *}=1$, and $p_{1 h}^{U *}=\left(\mu^{2} / 4\right) \mu+(\tau / 4)+1$.

Substituting these into utility equations, we obtain the optimal demand: $D_{1 h}=\left(2 \tau-\mu^{2} / 4(\tau+\mu)\right), D_{1 b}=\left(\mu^{2}+2 \mu\right.$ /4 $(\tau+\mu))$, and $D_{2}=(1 / 2)$, where $\tau>\tau_{1}=\left(\mu^{2} / 2\right)$

Similarly, the firm's profits in the product market are

$$
\left\{\begin{array}{l}
\pi_{1}^{U *}=\frac{\mu^{4}-4 \tau \mu^{2}+4 \mu+4 \tau(1+\tau)}{16(\tau+\mu)}, \\
\pi_{2}^{U *}=\frac{1}{4} .
\end{array}\right.
$$

Proposition 1. With unique preferences, the high-quality firm always chooses an upward extension for introducing a customized product. This strategy does not influence the profit of the low-quality firm.

Proposition 1 suggests that, with unique preferences, introducing an upward extension does not affect the competition between firms. This is because that introducing an upward extension just cannibalizes interfirm's market share, which does not influence the low-quality firm's demand $D_{2}=(1 / 2)$. Therefore, the competition between the two firms does not change, and the price and profit of the lowquality firm are the same as in the case that consumers have not unique preferences.

4.2.2. Downward Extension. When the high-quality firm introduces a low-quality customized product, three products with qualities $q_{1 b}>q_{1 l}>q_{2}$ are offered. The parameter $\theta_{1}$ represents the consumer who is indifferent between buying the low-quality firm's product with quality $q_{2}$ and the highquality firm's customized product with quality $q_{1 l}$. The parameter $\theta_{2}$ represents the consumer who is indifferent between buying the customized product with quality $q_{1 l}$ and base product with quality $q_{1 b}$ of the high-quality firm. The utility equations are as follows:

$$
\begin{aligned}
v+\theta_{1} q_{2}-p_{2} & =v+\theta_{1} q_{1 l}-p_{1 l}+\tau\left[1-\left(\theta_{2}-\theta_{1}\right)\right], \\
v+\theta_{2} q_{1 b}-p_{1 b} & =v+\theta_{2} q_{1 l}-p_{1 l}+\tau\left(1-\left(\theta_{2}-\theta_{1}\right)\right) .
\end{aligned}
$$

We obtain

$$
\begin{aligned}
\theta_{1}^{D *} & =\frac{\left(p_{1 l}-p_{2}-\tau\right) \mu-\tau\left(p_{1 b}-p_{2}\right)}{\mu-\mu^{2}+\tau}, \\
\theta_{2}^{D *} & =\frac{\left(p_{1 b}-p_{1 l}\right)(1-\mu)+\tau\left(1-\mu+p_{1 b}-p_{2}\right)}{\mu-\mu^{2}+\tau} .
\end{aligned}
$$

Substituting these parameters into firms' profits,

$$
\left\{\begin{array}{l}
\pi_{1}=\left(\theta_{2}-\theta_{1}\right)\left(p_{1 l}-c_{1 l}\right)+\left(1-\theta_{2}\right)\left(p_{1 b}-c_{1 b}\right), \\
\pi_{2}=\left(\theta_{1}\right)\left(p_{2}-c_{2}\right) .
\end{array}\right.
$$

Using first-order conditions, we $p_{2}^{D *}=(1 / 2)+\left(\mu\left(\mu^{2}-4 \mu-2 \tau\right) / 6(\tau+\mu)\right)$, $p_{1 b}^{D *}=1+\left(\mu\left(\mu^{2}-4 \mu-2 \tau\right) / 12(\tau+\mu)\right), \quad$ and $\quad p_{1 l}^{U *}=1-$ $\left(\left(-4 \mu^{3}+(16-3 \tau) \mu^{2}+8 \tau \mu-6 \tau^{2}\right) / 12(\tau+\mu)\right)$. The locations of the marginal consumers are, respectively, $\theta_{1}^{D *}=(1 / 2)-$ $\left(\mu\left(-\mu^{2}+\mu+2 \tau\right) / 6\left(-\mu^{2}+\mu+\tau\right)\right) \quad$ and $\theta_{2}^{U *}=(1 / 2)+$ $\left(\left(-3 \mu^{4}+(9-2 \tau) \quad \mu^{3}+(11 \tau-6) \mu^{2}+\left(4 \tau^{2}-12 \tau\right) \mu-6 \tau^{2}\right) /\right.$ $\left.12(\tau+\mu)\left(\mu^{2}-\mu-\tau\right)\right)$, where $\tau \leq \tau_{2}=2 \mu-\left(\mu^{2} / 2\right)$.

Similarly, firms' profits are

$$
\left\{\begin{array}{l}
\pi_{1}^{D *}=\frac{f_{1}^{D}(\mu, \tau)}{144(\tau+\mu)\left(\mu^{2}-\mu-\tau\right)} \\
\pi_{2}^{D *}=\frac{\left(\mu^{3}-4 \mu^{2}+(3-2 \tau) \mu+3 \tau\right)^{2}}{36(\tau+\mu)\left(\mu+\tau-\mu^{2}\right)}
\end{array}\right.
$$

where $f_{1}^{D}(\mu, \tau)=5 \mu^{6}-25 \mu^{5}+(8-29 \tau) \mu^{4}+(48+92 \tau) \mu^{3}+$ $\left(56 \tau^{2}-36\right) \mu^{2}-\left(84 \tau^{2}+72 \tau\right) \mu-36 \tau^{2}(1+\tau)$.

Proposition 2. If $L(\mu)<\tau<\tau_{2}$, the high-quality firm can still make more profit with a downward extension than with no extensions, where $L(\mu)=(\mu / 54)\left(A+\left(\mu^{2}+\right.\right.$ $132 \mu+792 / A)+28 \mu-42), \quad A=\sqrt[3]{\mu^{3}+198 \mu^{2}-31644 \mu}$ $+13392+162 \sqrt{-3 \mu^{4}-588 \mu^{3}+36708 \mu^{2}-41760 \mu-12096}$,

$L(\mu)$ increases with $\mu$, and $L(0)=0)$.

We focus our analysis on the region $L(\mu)<\tau<\tau_{2}$ (see Figure 1). Traditional research suggests that when a highquality firm competes with a low-quality firm, it generally introduces upward extensions $[16,17]$, as the same as our analysis in Lemma 1. However, this conclusion may not apply to introducing a customized product with consumers' unique preferences. If unique preferences are considered, the high-quality firm could make more profits when introducing a downward extension (in the shaded area). With unique preferences, consumers who buy the base product and customized product of the high-quality firm are separated into two social groups. The quality value of the base product $\left(q_{1 b}\right)$ is higher than that of the customized product $\left(q_{1 l}\right)$, and customized product enables consumers to have a uniqueness value. The differences in quality and uniqueness value increase the differentiation between the base product and customized product of the high-quality firm, which reduces the intrafirm cannibalization. On the one hand, the highquality firm charges a lower price for its base product than the case with no extensions $\left(p_{1 b}^{D *}<p_{1 b}^{N}\right)$, which reduces consumers' willingness to switch from the base product of the high-quality firm to the base product of the low-quality firm. Lower price increases the high-quality firm's demand for the base product $\left(\theta_{2}^{D *}<\theta_{2}^{D}\right)$. On the other hand, the high-quality firm charges a high price for its customized product because it is more valuable to consumers with unique preferences. The customized product appeals to more consumers who would otherwise buy the base product of the low-quality firm. Therefore, comparing with the results without unique preferences, the high-quality firm gains more market share and higher profits through charging a lower price of the base product and providing a customized 


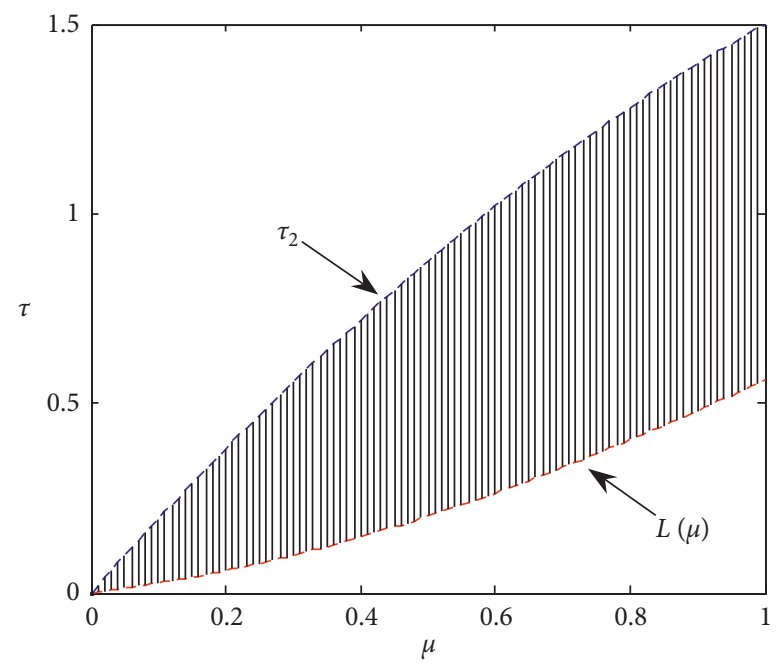

Figure 1: Profitable downward extensions with unique preferences.

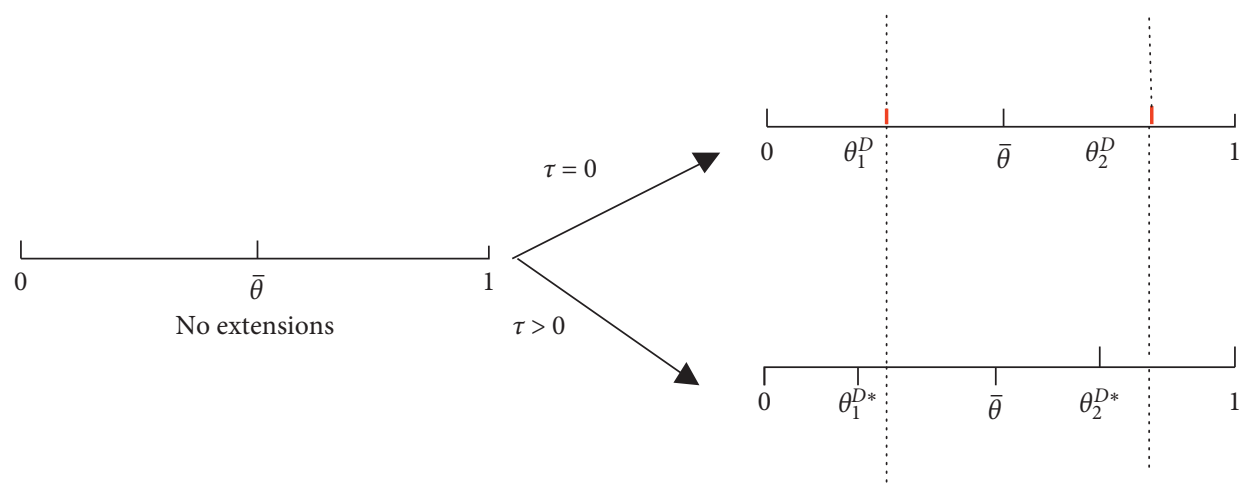

FIgURE 2: The distribution of consumers with a downward extension.

product (see Figure 2). At the same time, the downward extension of the high-quality firm intensifies competition between two firms, which reduces the low-quality firm's demand and profit $\left(\theta_{1}^{D *}<\theta_{1}^{D}\right)$.

To better understand the results, consider Figure 3 . Figure 3 depicts the changes of the location of marginal consumer $\theta$ and prices of the high-quality firm's products with the quality differentiation $\mu$. In Figure 3(a), considering consumers' unique preferences $(\tau=0.5)$, the high-quality firm sells the base product to high-type consumers, but it still intends to sell its customized product to some consumers who strongly prefer uniqueness. The increasing quality differentiation alleviates cannibalization in the product line of the high-quality firm $\left(\theta_{2}^{D *}<\theta_{2}^{D}\right)$. With increasing intrafirm quality differentiation, the quality differentiation between the high-quality firm's downward extension and the low-quality firm's product becomes lower, which makes the tough competition between two firms. The high-quality firm wants to target some of the low-type consumers who would buy the low-quality firm's product, which decreases the lowquality firm's market share $\left(\theta_{1}^{D *}<\theta_{1}^{D}\right)$. In Figure 3(b), when considering consumers' unique preferences $(\tau=0.5)$, the high-quality firm enhances the ability to extract prices premium for its products. When the high-quality firm introduces a downward extension, the prices of its products are higher than the case without unique preferences $\left(p_{1 b}^{D *}>p_{1 b}^{D}, p_{1 l}^{D *}>p_{1 l}^{D}\right)$. As a result of these effects, the highquality firm can increase profits by introducing a downward extension.

This occurs when consumers have the high sensitivity of uniqueness and the quality differentiation of the highquality firm's products is high. If the consumers have higher sensitivity, they will get more uniqueness value from the customized product. The high-quality firm has more incentive to introduce a downward extension and relax the pursuit of quality. The lower quality of the customized product obtains more revenues because of not only the costreduction effect but also the market-expanding effect.

This result is consistent with the observations of business practices. For example, in the sneakers industry, the highquality firms such as Nike compete with the low-quality firms in the market. According to Nike's website and latest annual report, Nike provides the high-end base products (i.e., AirForce and Air Max) in the high-end market and the low-end customized products (i.e., Roshe One By You, Internationalist By You, and Blazer Low By You) in the low- 


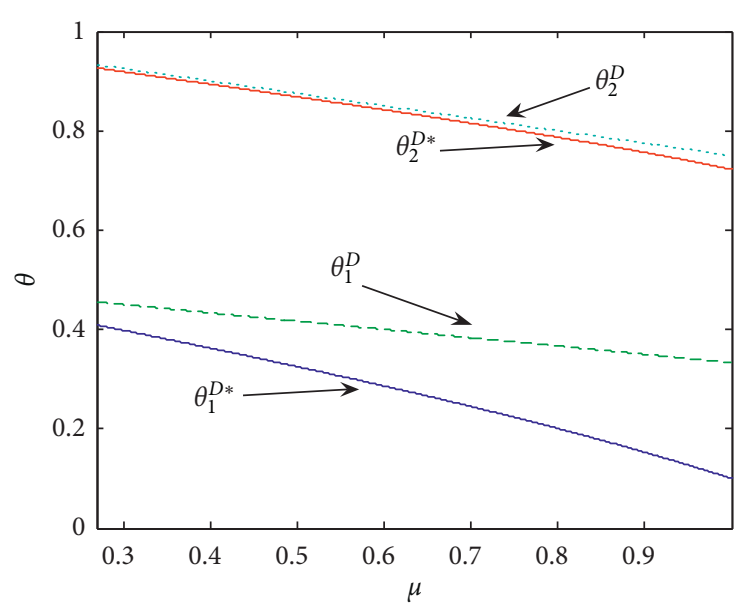

(a)

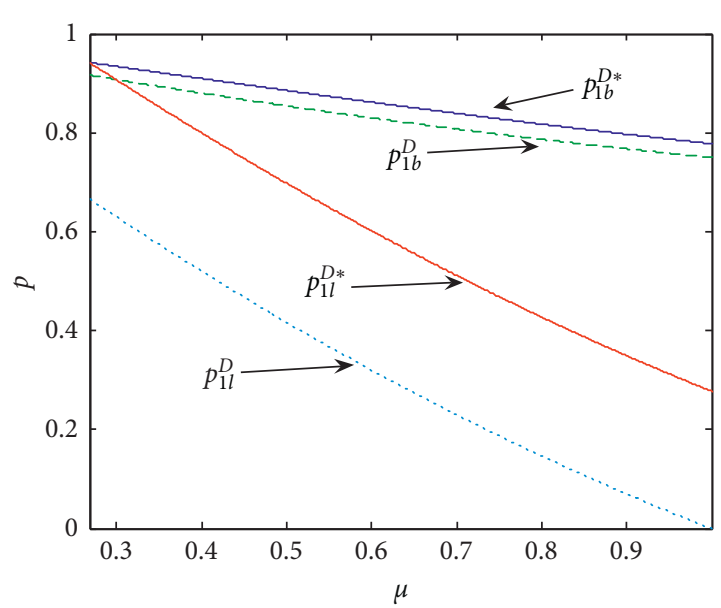

(b)

FIGURE 3: (a) The changes of the location of the marginal consumer with $\mu$. (b) The changes of prices of the high-quality firm's products with $\mu$ (dotted line: $\tau=0$ and solid line $\tau=0.5$ ).

end market competing with low-quality firms. Our model provides a rationale for why the high-quality firms could introduce downward extensions.

Lemma 2. With unique preferences, when the high-quality firm introduces a downward extension, the low-quality firm's profit decreases with $\mu$ and increases with $\tau\left(\left(\partial \pi_{2}^{D *} / \partial \mu\right)<0\right)$, $\left(\left(\partial \pi_{2}^{D *} / \partial \tau\right)>0\right)$.

As the analysis above, the high-quality firm's downward extension reduces the low-quality firm's profit. First, the low-quality firm's profit decreases with $\mu$ (see Figure 4). On the one hand, a higher value of $\mu$ corrodes the demand of the low-quality firm $\left(\left(\partial \theta_{1}^{D} / \partial \mu\right)=-\left(\mu^{4}-2 \mu^{3}+(1-\tau) \mu^{2}+\right.\right.$ $\left.\left.2 \tau \mu+2 \tau^{2} / 6\left(\mu+\tau-\mu^{2}\right)^{2}\right)<0\right)$. On the other hand, it would force the low-quality firm to reduce the price to serve the low-end market $\left(\left(\partial p_{2}^{D} / \partial \mu\right)=-\left(-2 \mu^{3}+(4-3 \tau) \mu^{2}+\right.\right.$ $\left.\left.8 \tau \mu+2 \tau^{2} / 6(\mu+\tau)^{2}\right)<0\right)$. Second, the low-quality firm's profit increases with $\tau$. On the one hand, the strong uniqueness sensitivity narrows the demand of low-quality firm $\left(\left(\partial \theta_{1}^{D} / \partial \tau\right)=-\left(\mu^{2}(1-\mu) / 6\left(\mu+\tau-\mu^{2}\right)^{2}\right)<0\right)$ because the customized product of the high-quality firm attracts some of the consumers who would buy the low-quality firm's product. On the other hand, the low-quality firm's price increases with the uniqueness sensitivity $\left(\left(\partial p_{2}^{D} / \partial \tau\right)=\left(\mu^{2}(2-\mu) / 6(\mu+\tau)^{2}\right)>0\right)$ because the lower uniqueness sensitivity of consumers, the fiercer competition between the low-quality firm's product and the high-quality firm's downward extension. However, the revenue from higher price offsets the loss in demand $\left|\left(\partial p_{2}^{D} / \partial \tau\right)\right|>\left|\left(\partial \theta_{1}^{D} / \partial \tau\right)\right|$, which causes the low-quality firm's profit to increase with the uniqueness sensitivity.

\subsubsection{Two Cases of Extensions}

Proposition 3. When $\tau_{1}<\tau<\tau_{m}$, where $\tau_{m}=\left(\left(4 \mu^{2}+14 \mu-9+3 \sqrt{25-12 \mu-4 \mu^{2}}\right) \mu / 8(\mu+3)\right)$, the high-quality firm tends to introduce an upward extension; when $\tau \geq \tau_{m}$, the high-quality firm tends to introduce a downward extension.

Proposition 3 states that the high-quality firm chooses different extension strategies with different uniqueness sensitivities (see Figure 5). Moreover, its profit is affected by the quality differentiation. First, when consumers' uniqueness sensitivity is low, we consider that the upward extension is still optimal when $\mu$ is large enough, which is consistent with the traditional research. However, the results suggest another possibility, namely that the high-quality firm could obtain more profits even if it introduces a downward extension. The revenue of the high-quality firm comes from the base product and the extensions. The profits in the two cases are, respectively, $\pi_{1}^{D}=\pi_{1 b}^{D}+\pi_{1 l}^{D}, \quad \pi_{1}^{U}=\pi_{1 b}^{U}+\pi_{1 h}^{U}$, and $\pi_{1 b}^{D}<\pi_{1 b}^{U}$ and $\pi_{1 l}^{D}>\pi_{1 h}^{U}$. The revenue of the base product increases with $\mu$; the revenue of the customized product decreases with $\mu$ in two cases. However, when consumers are less sensitive to uniqueness, they gain less value from the customized product. If $\mu$ is small enough, $\pi_{1 h}^{U}$ decreases sharply with the increase of $\mu\left(\partial \pi_{1 h}^{U} / \partial \mu\right)<\left(\partial \pi_{1 l}^{D} / \partial \mu\right)<0$. If $\mu$ increases to a threshold, $\pi_{1 h}^{U}$ decreases slowly with the increase of $\mu\left(\partial \pi_{1 l}^{D} / \partial \mu\right)<\left(\partial \pi_{1 h}^{U} / \partial \mu\right)<0$. As a result, when consumers' uniqueness sensitivity is low, the downward extension is more profitable with a lower $\mu$; the upward extension is better with a higher $\mu$.

Second, when consumers are more sensitive to uniqueness, they gain more uniqueness value from the customized product, so the high-quality firm tends to introduce a downward extension. Specifically, when the uniqueness sensitivity is high, the high-quality firm's incentives for introducing a downward extension are more intense, and it inclines to expand the quality differentiation of products. That is because as consumers' unique preferences increase, fewer consumers purchase the low-quality firm's base product (as shown in Figure 3(a), $\theta_{1}^{D}$ decreases). And more importantly, the trend is more obvious with 


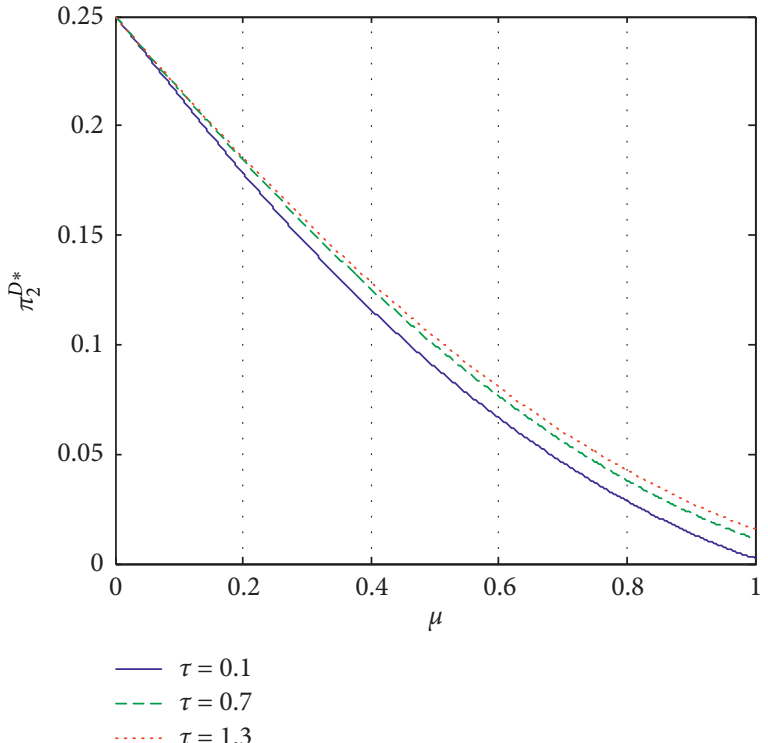

FIGURE 4: The changes of low-quality firm's profit with $\mu$ under different values of $\tau$.

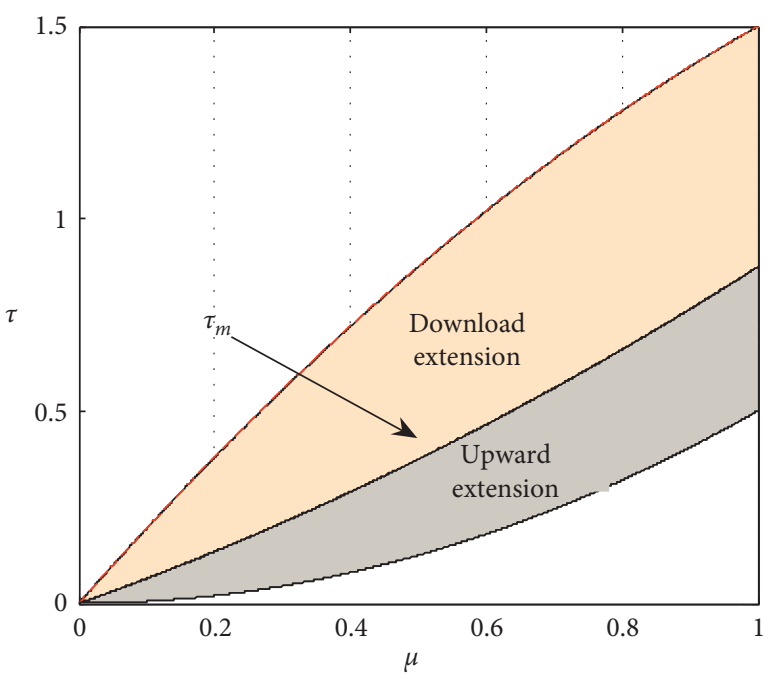

FIgURE 5: The strategic choices of the high-quality firm.

increasing the quality differentiation of products $(\mu)$. So, it means that more consumers will switch from the low-quality firm's base product to the high-quality firm's downward extension. Besides, although the high-quality firm has an incentive to reduce prices with increasing the quality differentiation of products (as shown in Figure 3(b)), the first effect (business stealing) helps the high-quality firm. If the high-quality firm makes an upward extension, $\pi_{1 h}^{U}$ always decreases sharply with the increase of $\mu\left(\partial \pi_{1 h}^{U} / \partial \mu\right)<\left(\partial \pi_{1 l}^{D} / \partial \mu\right)<0$. Even if $\mu$ is large enough, there is no guarantee that the high-quality firm will benefit more from an upward extension. In this case, according to the actual condition $\left(\left(4 \mu^{2}+14 \mu-9+3 \sqrt{25-12 \mu-4 \mu^{2}}\right) \mu / 8(\mu+\right.$ $3))<$ $\tau<2 \mu-\left(\mu^{2} / 2\right)$, the high-quality firm should ensure a higher-quality differentiation of products to introduce a downward extension.

This result complements the widespread results in the past literature on vertical line extensions showing that when a high-quality firm competes with a low-quality firm, it generally introduces upward extensions [16, 17]. In the previous research, products are differentiated along a single vertical (quality-type) attribute, and consumers' willingness to pay can be ordered along that single dimension. However, our paper captures vertical and horizontal differentiation by introducing customization technology. Consumers' unique preferences alleviate the firm's pressure on quality improvement, and cost saving increases its profit. In reality, consumers play a more active role in categories that facilitate expressing themselves or that are status symbols, such as clothing, footwear, jewelry, and fashion accessories [32]. This result is consistent with observations of practices. For example, in the footwear industry, comparing secondary data from cyLEDGE Media Configurator Database (http:// www.configurator-database.com) and Adidas (https://www. adidas.com.cn), Adidas introduced its 42 downward extensions (¥299-¥500) in these years.

Proposition 4. With unique preferences, the high-quality firm (a) introducing a downward extension would reduce the low-quality firm's profit; (b) introducing an upward extension does not affect the low-quality firm's profit.

Proposition 4 shows that these conclusions are consistent about how the vertical line extensions of the highquality firm affect the low-quality firm's profit, regardless of whether or not consumers' unique preferences are taken into account (Lemma 1).

\section{Extensions}

In Section 4, we examine how the high-quality firm selling a base product introduces a customized product in a vertical differentiation model. In this section, we analyse how the low-quality firm introduces product line extensions when facing a high-quality firm.

5.1. The Low-Quality Firm's Product Line Extensions. Following the assumptions in Section 4, we assume that firm 1 (the high-quality firm) offers a high-quality product $q_{1}$ and firm 2 (the low-quality firm) offers a base product $q_{2 b}$. The firm 2 decides whether to introduce an upward extension $\left(q_{2 h}>q_{2 b}\right)$ or a downward extension $\left(q_{2 l}<q_{2 b}\right)$. We also assume that $q_{2 h}-q_{2}=q_{2}-q_{2 l}=\mu$ and $q_{1}-q_{2 b}=1$. The marginal cost of products are, respectively, $c_{2 l}=\left(q_{2 l}^{2} / 2\right)$, $c_{2 b}=\left(\left(q_{2 l}+\mu\right)^{2} / 2\right), \quad c_{2 h}=\left(\left(q_{2 l}+2 \mu\right)^{2} / 2\right), \quad$ and $c_{1}=\left(\left(q_{2 l}+1+\mu\right)^{2} / 2\right)$. To simplify analysis, we standardize the marginal cost of firm 2's downward extension to zero, that is, $q_{2 l}=0$.

Proposition 5. When the low-quality firm wants to expand the product line through introducing customization technology, 
(1) Without unique preferences, the low-quality firm always introduces a downward extension; with unique preferences, an upward extension is profitable for the low-quality firm when the uniqueness sensitivity is high

(2) With unique preferences, if the quality differentiation $\mu$ between base product and extensions is small, the low-quality firm tends to introduce an upward extension; otherwise, it tends to introduce a downward extension

Without consumers' unique preferences, an upward extension of the low-quality firm represents a lowerquality differentiation from the competitor's product, which intensifies competition between two firms and reduces its profits. However, when consumers exhibit unique preferences, introducing an upward extension is profitable for the low-quality firm. Table 1 summarizes the low-quality firm's prices, demands, and profits in different cases.

We further explain why an upward extension is profitable for the low-quality firm. First, comparing with the case that without unique preferences $(\tau=0)$, the increase in $\tau$ increases the uniqueness value of the customized product, enticing consumers to switch from buying the low-quality firm's base product to buying its upward extension, which makes $\theta_{1}^{U *}$ moves to the left, see Figure 6. Second, an upward extension provides a customized product with a higher quality, enticing consumers to switch from buying the high-quality firm's product to buying the low-quality firm's upward extension, which makes $\theta_{2}^{U *}$ moves to the right. The low-quality firm extracts more consumer surplus in $\left[\theta_{1}^{U *}, \theta_{2}^{U *}\right]$, which alleviates cannibalization in the product line.

Moreover, as the quality differentiation decreases, the low-quality firm may change from introducing a downward extension to an upward extension (see Figure 7). If the lowquality firm that intends to introduce an upward extension increases the quality differentiation between its base product and customized product, the effect of rising cost outweighs the benefits from introducing an upward extension. Therefore, the low-quality firm can highlight the advantage of upward extension when the quality differentiation is small.

In addition, the upward extension of the low-quality firm reduces the high-quality firm's profit. It is because that the upward extension intensifies competition between the two firms. With unique preferences, the low-quality firm can charge a higher price premium for its customized product, which forces the high-quality firm to reduce its price. As a result, the high-quality firm's profit reduces as its product's price and demand decrease $\left(\theta_{2}^{U *}>\bar{\theta}\right)$.

5.2. The Low-Quality Firm's Cost. In the main model, we assume $q_{2}=0$. Now, we relax our assumption to check the robustness of our results in a general framework. Suppose $q_{2}=q>0$ and present some statistical analysis.
Proposition 6. Considering the production cost of the lowquality firm, when the high-quality firm wants to expand product line through introducing customization technology,

(a) Without unique preferences, the high-quality firm always introduces an upward extension; with unique preferences, a downward extension is also profitable when the uniqueness sensitivity is high, and its profit is increasing with the quality (q) of the low-quality firm's product.

(b) If the unique sensitivity is small $\tau$, an upward extension is profitable for the high-quality firm as long as its quality differentiation is big, and its profit increases with q. Otherwise, the high-quality firm introduces a downward extension.

Without unique preferences, the high-quality firm always introduces an upward extension when $q$ is small. With unique preferences, the high-quality firm introduces a downward extension under a range of situations (see Figure 8 ). Figure 8 shows that the profit differentiation of the high-quality firm between the upward extension and no extensions $\left(\Delta \pi=\pi_{1}^{D *}(q)-\pi_{1}^{N}(q)\right)$ changes with parameters. When $q$ is small, there is a region that the downward extension is profitable, and the high-quality firm's profit increases with the competitor's production cost.

Similarly, Figure 9 shows the profit differentiation of the high-quality firm between the upward extension and the downward extension. From this figure, we can see that the downward extension is more profitable in most situations. However, if the uniqueness sensitivity is small, the highquality firm that intends to introduce an upward extension should increase the quality differentiation between its products. In addition, it is more advantageous for the highquality firm to introduce an upward extension with the increase of the competitor's production cost.

We also find that the changes of $q$ do not affect the conclusions that introducing a downward extension of the high-quality firm reduces the low-quality firm's profit and introducing an upward extension does not affect the lowquality firm's profit.

5.3. Impact of the Fixed Cost for Offering Product Customization. We now consider the impact of the fixed cost for offering product customization on the equilibrium outcome. Firstly, the fixed cost does not have any effect on the equilibrium pricing decisions. Secondly, the fixed cost only impacts whether the firm would offer a customized product when it introduces the product line extensions. Let $F$ denote the fixed cost for introducing an upward or a downward extension.

Proposition 7. When the high-quality firm tends to expand the product line through introducing customization technology, the fixed cost for introducing an extension is F:

(a) When $\tau_{1}<\tau<\tau_{m}$, if $F<\pi_{1}^{U *}-\pi_{1}^{N}$, the high-quality firm tends to introduce an upward extension and, if $F \geq \pi_{1}^{U *}-\pi_{1}^{N}$, it makes no extensions 
TABLE 1: Equilibrium outcomes when the low-quality firm expands the product line.

\begin{tabular}{|c|c|c|c|}
\hline- & No extensions & Upward extension & Downward extension \\
\hline$\theta_{1}$ & $((1 / 3) \mu+(1 / 2))$ & $\left(\left(9 \mu^{4}+(6 \tau-9) \mu^{3}-15 \tau \mu^{2}-8 \tau^{2} \mu\right) /\left(12(\tau+\mu)\left(\mu^{2}-\mu-\tau\right)\right)\right)$ & $\left(\mu^{2}+2 \tau / 4(\mu+\tau)\right)$ \\
\hline$\theta_{2}$ & - & $\left(3 \mu^{3}-(4 \tau+3) \mu-3 \tau / 6\left(\mu^{2}-\mu-\tau\right)\right)$ & $((1 / 3) \mu+(1 / 2))$ \\
\hline$p_{1}$ & $\left((1 / 2) \mu^{2}+(2 / 3) \mu+1\right)$ & $1+\left(\mu\left(6 \mu^{2}+3 \tau \mu+2 \tau\right) / 6(\mu+\tau)\right)$ & $\left((1 / 2) \mu^{2}+(2 / 3) \mu+1\right)$ \\
\hline$p_{2 b}$ & $\left((1 / 2) \mu^{2}+(1 / 3) \mu+(1 / 2)\right)$ & $(1 / 2)+\left(\mu\left(9 \mu^{2}+6 \tau \mu+2 \tau\right) / 12(\mu+\tau)\right)$ & $\left((1 / 2) \mu^{2}+(1 / 3) \mu+(1 / 2)\right)$ \\
\hline$p_{2 h}$ & - & $\left(\left(6 \tau^{2}+\left(15 \mu^{2}+8 \mu\right) \tau+18 \mu^{3}\right) / 12(\mu+\tau)\right)+(1 / 2)$ & (1) \\
\hline$p_{2 l}$ & - & - & $\left((1 / 4) \mu^{2}+(1 / 3) \mu+(1 / 2) \tau+(1 / 2)\right)$ \\
\hline$\pi_{1}$ & $(1 / 36)(3-2 \mu)^{2}$ & $\left(\left[-3 \mu^{3}+6 \mu^{2}+(4 \tau-3) \mu-3 \tau\right]^{2} / 36\left(\mu+\tau-\mu^{2}\right)(\tau+\mu)\right)$ & $(1 / 36)(3-2 \mu)^{2}$ \\
\hline$\pi_{2}$ & $(1 / 36)(3+2 \mu)^{2}$ & $\left(G^{1} /\left(144(\tau+\mu)\left(\mu^{2}-\mu-\tau\right)\right)\right)$ & $\left(H^{2} / 144(\tau+\mu)\right)$ \\
\hline & den & $22-93 \tau) \mu^{4}+180 \tau \mu^{3}+\left(80 \tau^{2}-96 \tau-3\right.$ & $-36 \tau^{2}(1+\tau)$ \\
\hline
\end{tabular}

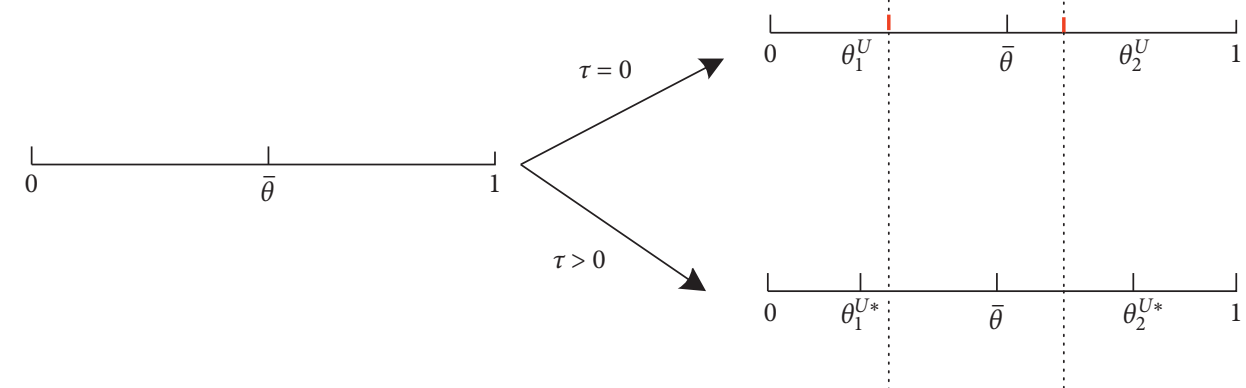

FIgURE 6: The location of marginal consumers (no extensions vs. upward extension).

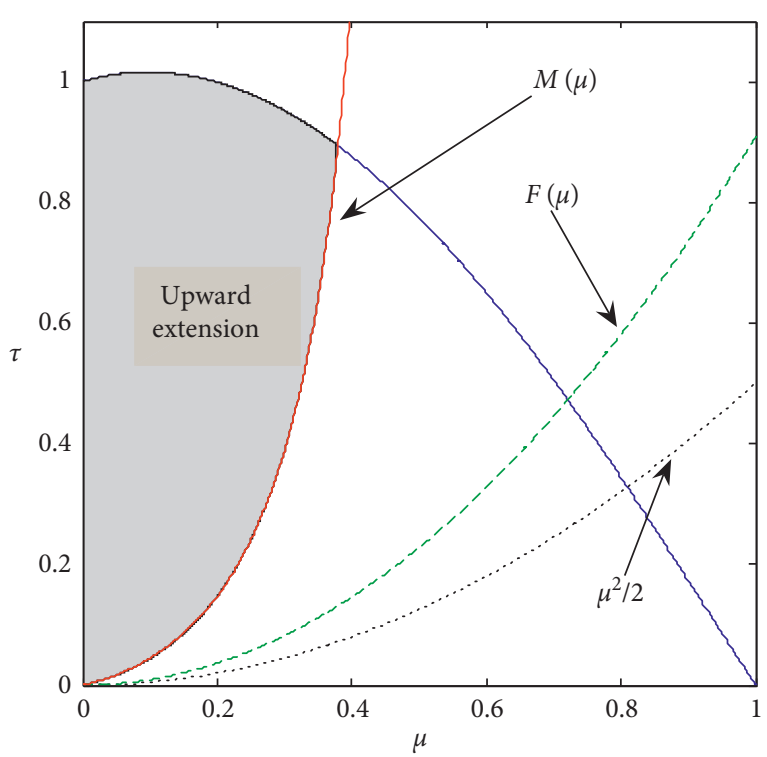

Figure 7: The strategic choices of the low-quality firm.

(b) When $\tau_{m} \leq \tau<\tau_{2}$, if $F<\pi_{1}^{D *}-\pi_{1}^{N}$, the high-quality firm tends to introduce a downward extension and, if $F \geq \pi_{1}^{D *}-\pi_{1}^{N}$, it makes no extensions

Figure 10 graphically depicts the results of Proposition 7 (note: in this Figure, the value of $\pi_{1}^{D *}-\pi_{1}^{N}$ and $\pi_{1}^{U *}-\pi_{1}^{N}$ depends on the values $\tau$ and $\mu$, and they do not denote the

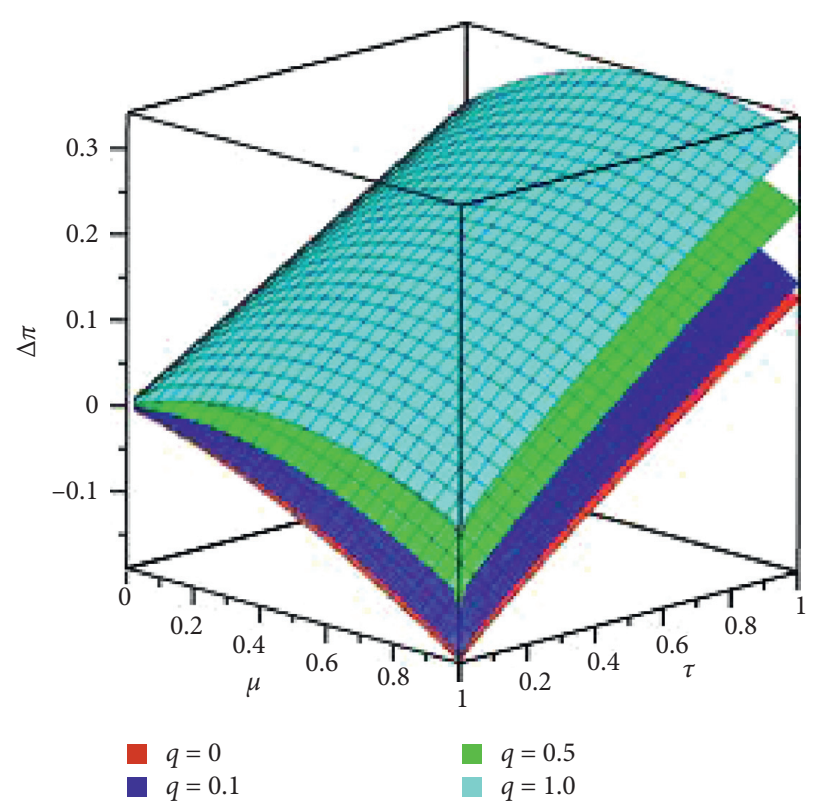

Figure 8: The changes of $\left(\Delta \pi=\pi_{1}^{D *}(q)-\pi_{1}^{N}(q)\right)$.

value of $\pi_{1}^{D *}-\pi_{1}^{N}$ is greater than $\left.\pi_{1}^{U *}-\pi_{1}^{N}\right)$. The figure shows that an important factor that influences the equilibrium is the fixed cost. For part (a) of Proposition 7, when $\tau_{1}<\tau<\tau_{m}$, it is understandable that if the fixed cost is low, the equilibrium outcome is the same as Proposition 3. However, if the value of fixed cost is moderate 


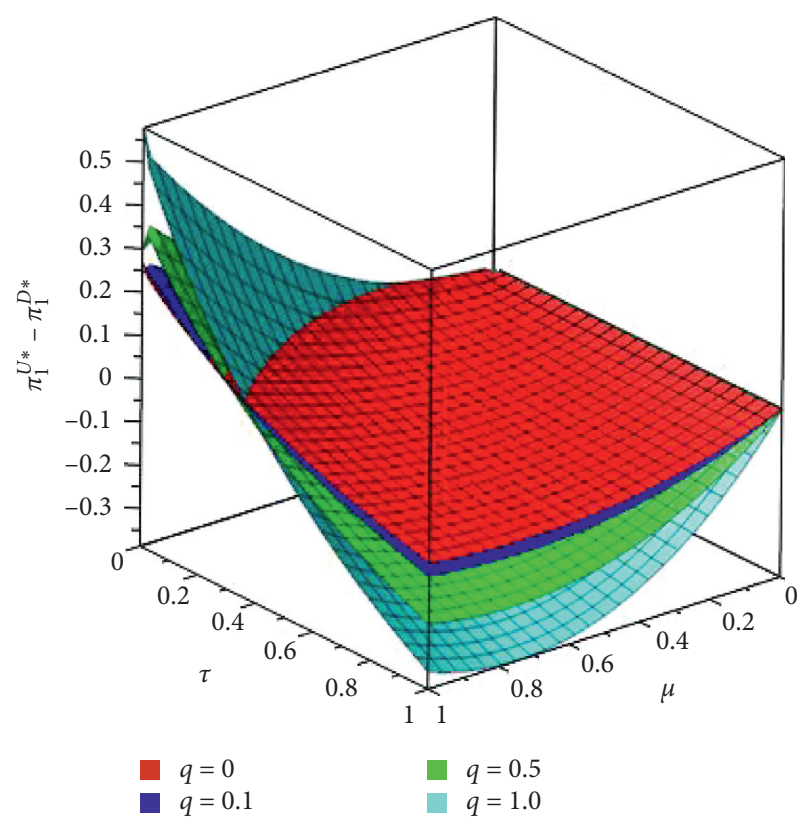

FIgURE 9: The changes of $\left(\Delta \pi=\pi_{1}^{U *}(q)-\pi_{1}^{D *}(q)\right)$.

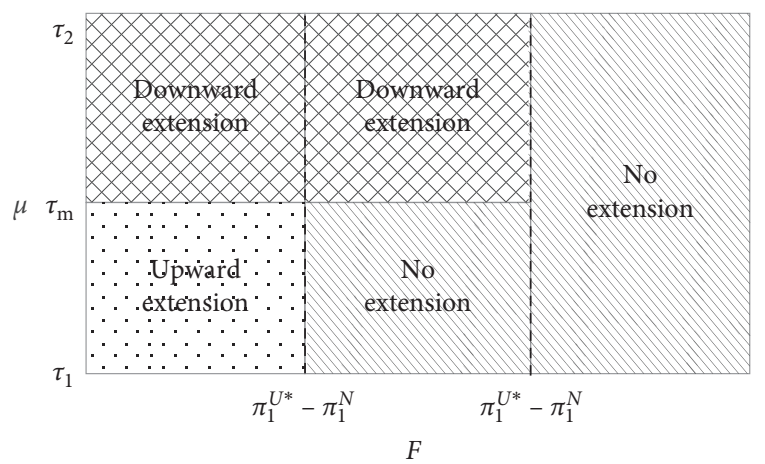

Figure 10: The equilibrium strategies of the high-quality firm.

$\left(\pi_{1}^{D *}-\pi_{1}^{N}>F \geq \pi_{1}^{U *}-\pi_{1}^{N}\right)$, the high-quality firm tends to make no extensions, unless the value of $\tau$ is high $\left(\tau_{m} \leq \tau<\tau_{2}\right)$. In other words, when the value of $\tau$ is high $\left(\tau_{m} \leq \tau<\tau_{2}\right)$, the high-quality firm only considers a downward extension. Of course, it is understandable that if the fixed cost is high, it is unwise for the high-quality firm to provide customized products for consumers.

\section{Conclusions and Implications}

In this paper, we have studied how firms selling base products introduce customized products in a vertical differentiation model when they take consumers' unique preferences into account. We use a game-theoretic model to investigate how consumers' unique preferences and quality differentiation affect a firm's decisions on vertical line extensions and competition between the two firms. We offer the following theoretical and practical implications.

Consumers' unique preferences affect firms' decisions on vertical line extensions. Without unique preferences, the high-quality firm always introduces an upward extension.
However, considering consumers' unique preferences, a downward extension is still profitable within a certain feasible range.

Consumers' unique preferences do (not) affect competition between the two firms. With or without unique preferences, introducing an upward extension ( $U$ strategy) of the highquality does not affect the low-quality firm's profit, but introducing a downward extension ( $D$ strategy) reduces the low-quality firm's profit.

The quality differentiation between the base product and extensions affects the high-quality firm's decisions on vertical line extensions. When the uniqueness sensitivity is low, a high-quality firm that intends to introduce an upward extension should increase its quality differentiation. Otherwise, a download extension may be a better choice for it.

The quality differentiation between the base product and extensions affects the low-quality firm's decisions on vertical line extensions. Similarly, a downward extension is a better choice for the low-quality firm. However, an upward extension is more profitable, when its quality differentiation is small. Table 2 summarizes firms' decisions on vertical line extensions as consumers' unique preferences and quality differentiation change.

Our results give some interesting practical insights. First, it is widely believed among marketing and operations scholars that firms generally improve the basic value of products by quality improvement to attract more consumers. Customized products provide firms with more possibilities to meet the diversified needs of consumers. Our results show that firms can obtain more revenue by introducing customization technology, so firms should pay more attention on the value perception of uniqueness. They can focus on improving product satisfaction (uniqueness and experience of product: function, structure, and appearance) and process satisfaction (enjoyment, creation, and selfgratification).

Second, firms choose different product line extensions according to their position and product type. Firms should make sure their position in the market because the quality level of products affects the option of extending upwards or downwards. In addition, the uniqueness sensitivity varies for different types of products. The high sensitivity encourages high-quality firms to introduce downward extensions and low-quality firms to introduce upward extensions through customization technology. At a very broad strategic level, our results show that firms need to fully evaluate their position and product type and explore market conditions to make decisions on vertical line extensions.

Finally, our findings can be very practical for marketing managers. We have shown the strategic roles of customized products attracting consumers who have unique preferences. Our findings might advocate a need for firms to cultivate consumers' uniqueness consciousness through advertising and other marketing methods. For example, when firms introduce customized products, they could use media platforms to deliver the information promoting a sense of independence, which induces the consumers' unique consciousness, such as Adidas's slogan "impossible is nothing" and Puma "always be yourself." Our discussion 
TABLe 2: Summary of research conclusions.

The high-quality firm's vertical The low-quality firm's vertical line extensions line extensions

\begin{tabular}{lccccc}
\hline$\tau$ & $\mu$ & Extensions & $\tau$ & $\mu$ & Extensions \\
\hline Smaller & $\begin{array}{c}\text { Smaller } \\
\text { Bigger }\end{array}$ & $\begin{array}{c}\text { Downward } \\
\text { Upward }\end{array}$ & Smaller & $\begin{array}{c}\text { Smaller } \\
\text { Bigger }\end{array}$ & $\begin{array}{c}\text { Upward } \\
\text { Downward }\end{array}$ \\
\hline Bigger & - & Downward & Bigger & - & Upward \\
\hline
\end{tabular}

highlights the importance of accounting for the different dimensions of consumer valuation and product variety in product line extension strategies.

We acknowledge some caveats in this paper regarding the model and results. To make the results more tractable and explicit, we set the quality differentiation to be consistent, whether introducing an upward extension or a downward extension. Relaxing this assumption may generate more insights into the role of quality differentiation. In addition, we assume consumers have the same uniqueness sensitivity to customized products. This may be far from realistic because consumers even with unique preferences can be heterogeneous on customized products. It may become more likely that firms adopt different vertical extension strategies trying to capture different customer segments. Further research is needed in all those directions to confirm the results in this paper.

\section{Appendix}

Proof of Lemma 1. In case 1, we calculate the first-order derivative of profits functions with respect to $p_{1 b}, p_{2}$, respectively, from equation (3), and obtain the results $p_{1 b}^{N}=1$, $p_{2}^{N}=(1 / 2)$, and $\bar{\theta}=(1 / 2)$. Inserting these results into equation (3), we can further obtain the profits: $\pi_{1}^{N}=(1 / 4)$ and $\pi_{2}^{N}=(1 / 4)$.

In Case 2, the two firms' profits are expressed as follows:

$$
\left\{\begin{array}{l}
\pi_{1}=\left(\theta_{2}-\theta_{1}\right)\left(p_{1 b}-c_{1 b}\right)+\left(1-\theta_{2}\right)\left(p_{1 h}-c_{1 h}\right), \\
\pi_{2}=\left(\theta_{1}\right)\left(p_{2}-c_{2}\right) .
\end{array}\right.
$$

We calculate the first-order derivative of profit functions with respect to $p_{1 h}, p_{1 b}$, and $p_{2}$, respectively, from equation (A.1), and obtain the results $p_{2}^{U}=(1 / 2), p_{1 b}^{U}=1$, and $p_{1 h}^{U}=\left(\mu^{2} / 4\right)+\mu+1$. Inserting these results into equation (A.1), we can obtain the profits of the upward extension equation (4).

In case $\mathrm{HD}$, the two firms' profits are expressed as follows:

$$
\left\{\begin{array}{l}
\pi_{1}=\left(\theta_{2}-\theta_{1}\right)\left(p_{1 l}-c_{1 l}\right)+\left(1-\theta_{2}\right)\left(p_{1 b}-c_{1 b}\right), \\
\pi_{2}=\left(\theta_{1}\right)\left(p_{2}-c_{2}\right) .
\end{array}\right.
$$

We calculate the first-order derivative of profit functions with respect to $p_{1 l}, p_{1 b}$, and $p_{2}$, respectively, from equation (A.2), and obtain the results $p_{2}^{D}=\left(\left(\mu^{2}-4 \mu+3\right) / 6\right)$, $p_{1 b}^{D}=\left(\left(\mu^{2}-4 \mu+12\right) / 12\right), \quad p_{1 l}^{D}=\left(\left(\mu^{2}-4 \mu+3\right) / 3\right), \quad \theta_{1}^{D}=$ $((3-\mu) / 6)$, and $\theta_{2}^{D}=((4-\mu) / 4)$. Inserting these results into equation (A.2), we can obtain the profits of the downward extension equation (5).
Then, we compare the high-quality firm's profits of the upward extension and no extensions $\pi_{1}^{U}-\pi_{1}^{N}>0$ and profits of the downward extension and no extensions $\pi_{1}^{D}-\pi_{1}^{N}=$ $\left(\mu\left(5 \mu^{2}-20 \mu-12\right) / 144\right)<0 \quad(0<\mu<1)$.

Proof of Proposition 1. We calculate the first-order derivative of profit functions with respect to $p_{1 h}, p_{1 b}$, and $p_{2}$, respectively, from equation (6), and obtain the results $p_{2}^{U *}=(1 / 2), p_{1 b}^{U *}=1, p_{1 h}^{U *}=\left(\mu^{2} / 4\right)+\mu+(\tau / 4)+1, \theta_{1}^{U *}=$ (1/2), and $\theta_{2}{ }^{*}=\left(\mu^{2}+4 \mu+2 \tau / 4(\tau+\mu)\right)$. Inserting these results into equation (6), we can obtain the profits of firms:

$$
\left\{\begin{array}{l}
\pi_{1}^{U *}=\frac{\mu^{4}-4 \tau \mu^{2}+4 \mu+4 \tau(1+\tau)}{16(\tau+\mu)} \\
\pi_{2}^{U *}=\frac{1}{4}
\end{array}\right.
$$

The necessary condition is $\tau>\tau_{1}=\left(\mu^{2} / 2\right)$. This proof is simple and easily demonstrated as in Lemma 1 .

Proof of Proposition 2. From equation (10), we calculate the first-order derivative of profit functions with respect to $p_{2}$, $p_{1 b}$, and $p_{1 l}$, respectively, and obtain the results

$$
\begin{aligned}
& p_{2}^{D *}=\frac{1}{2}+\frac{\mu\left(\mu^{2}-4 \mu-2 \tau\right)}{6(\tau+\mu)}, \\
& p_{1 b}^{D *}=1+\frac{\mu\left(\mu^{2}-4 \mu-2 \tau\right)}{12(\tau+\mu)}, \\
& p_{1 l}^{U *}=1-\frac{-4 \mu^{3}+(16-3 \tau) \mu^{2}+8 \tau \mu-6 \tau^{2}}{12(\tau+\mu)}, \\
& \theta_{1}^{D *}=\frac{1}{2}-\frac{\mu\left(-\mu^{2}+\mu+2 \tau\right)}{6\left(-\mu^{2}+\mu+\tau\right)}, \\
& \theta_{2}^{U *}=\frac{1}{2}+\frac{-3 \mu^{4}+(9-2 \tau) \mu^{3}+(11 \tau-6) \mu^{2}+\left(4 \tau^{2}-12 \tau\right) \mu-6 \tau^{2}}{12(\tau+\mu)\left(\mu^{2}-\mu-\tau\right)} .
\end{aligned}
$$

Inserting these results into equation (10), we can obtain the profits of firms:

$$
\left\{\begin{array}{l}
\pi_{1}^{D *}=\frac{f_{1}^{D}(\mu, \tau)}{144(\tau+\mu)\left(\mu^{2}-\mu-\tau\right)}, \\
\pi_{2}^{D *}=\frac{\left(\mu^{3}-4 \mu^{2}+(3-2 \tau) \mu+3 \tau\right)^{2}}{36(\tau+\mu)\left(\mu+\tau-\mu^{2}\right)},
\end{array}\right.
$$

$$
\begin{aligned}
f_{1}^{D}(\mu, \tau)= & 5 \mu^{6}-25 \mu^{5}+(8-29 \tau) \mu^{4}+(48+92 \tau) \mu^{3} \\
& +\left(56 \tau^{2}-36\right) \mu^{2}-\left(84 \tau^{2}+72 \tau\right) \mu-36 \tau^{2}(1+\tau),
\end{aligned}
$$


and the necessary condition is $\left(\tau \leq \tau_{2}=2 \mu-\left(\mu^{2} / 2\right)\right)$.

From the conclusions of Lemma 1, we can easily obtain $\left(\Delta \pi_{D N}=\pi_{1}^{D *}-\pi_{1}^{N}=\left(f_{1 b}^{D}(\mu, \tau) /\right.\right.$ $\left.\left.\left(144(\tau+\mu)\left(\mu^{2}-\mu-\tau\right)\right)\right)-(1 / 4)\right)$. Let $\left(\Delta \pi_{D N}=0\right)$, and we can obtain

$$
\begin{aligned}
\tau^{*} & =L(\mu)=\frac{\mu}{54}\left(A+\frac{\mu^{2}+132 \mu+792}{A}+28 \mu-42\right), \\
A & =\sqrt[3]{\mu^{3}+198 \mu^{2}-31644 \mu+13392+162 \sqrt{-3 \mu^{4}-588 \mu^{3}+36708 \mu^{2}-41760 \mu-12096}} .
\end{aligned}
$$

We can verify $((\partial L(\mu) / \partial \mu)>0)$, and $L(0)=0$. When $\tau>L(\mu), \Delta \pi_{D N}>0$. In addition, the above solution is valid in the constraints: $\tau_{1}=\left(\mu^{2} / 2\right)<L(\mu)<\tau_{2}=2 \mu-\left(\mu^{2} / 2\right)$.

Proof of Lemma 2. From the conclusions of Proposition 2, we calculate the first-order derivative of $\pi_{2}^{D *}$ with respect to $\tau$, respectively, and we obtain

$$
\begin{aligned}
\frac{\partial \pi_{2}^{D *}}{\partial \tau}= & \frac{\mu^{2}}{36(\tau+\mu)^{2}\left(\mu+\tau-\mu^{2}\right)^{2}}\left[\mu^{3}-4 \mu^{2}+(3-2 \tau) \mu+3 \tau\right] \\
& \cdot\left[\mu^{3}-2 \mu^{2}+\mu+\tau\right] .
\end{aligned}
$$

Since $0<\mu<1$ and $\left(\mu^{2} / 2\right)<\mu<2 \mu^{2}-(\mu / 2)$, we have $\mu^{3}-$ $4 \mu^{2}+(3-2 \tau) \mu+3 \tau>0$ and $\mu^{3}-2 \mu^{2}+\mu+\tau>0$; then, $\left(\partial \pi_{2}^{D *} / \partial \tau\right)>0$. Similarly, $\left(\partial \pi_{2}^{D *} / \partial \mu\right)<0$.
Proof of Proposition 3. From the conclusions of Propositions 1 and 2, we obtain

$$
\begin{gathered}
\Delta \pi=\pi_{1}^{U *}-\pi_{1}^{D *}=\frac{\mu F(\mu, \tau)}{36(\tau+\mu)\left(\mu^{2}-\mu-\tau\right)}, \\
F(\mu, \tau)=\mu^{5}+4 \mu^{4}-(2+4 \tau) \mu^{3}-(3+14 \tau) \mu^{2} \\
+\left(9 \tau+4 \tau^{2}\right) \mu+12 \tau^{2} . \\
\text { Let } \quad \Delta \pi=0, \quad \text { and we obtain } \tau_{m}=\left(\left(4 \mu^{2}+\right.\right. \\
\left.\left.14 \mu-9+3 \sqrt{25-12 \mu-4 \mu^{2}}\right) \mu / 8(\mu+3)\right) . \text { Since } \mu \in(0,1), \\
\text { we have } \tau_{2}>\tau_{m}>\tau_{1} . \text { When } \tau_{m}>\tau>\tau_{1}, \Delta \pi=0 \text {; when } \tau_{m} \leq \tau,
\end{gathered}
$$
$\Delta \pi=0$.

Proof of Proposition 4. From the conclusions above, we obtain

$$
\begin{aligned}
\pi_{2}^{D *}-\pi_{2}^{N} & =\frac{\left(\mu^{3}-4 \mu^{2}+(3-2 \tau) \mu+3 \tau\right)^{2}}{36(\tau+\mu)\left(\mu+\tau-\mu^{2}\right)}-\frac{1}{4} \\
& =\frac{\mu\left[\mu^{5}-8 \mu^{4}+(22-4 \tau) \mu^{3}+(22 \tau-15) \mu^{2}+\left(4 \tau^{2}-9 \tau\right) \mu-12 \tau^{2}\right]}{36(\tau+\mu)\left(\mu+\tau-\mu^{2}\right)}<0, \\
\pi_{2}^{U *}-\pi_{2}^{N} & =0 .
\end{aligned}
$$

Proof of Proposition 5. In firm 2 with no extensions, we get $\left(p_{1}^{N}=(1 / 2) \mu^{2}+(2 / 3) \mu+1\right) \quad\left(p_{2 b}^{N}=(1 / 2) \mu^{2}+(1 / 3) \mu+\right.$ $(1 / 2)), \quad(\bar{\theta}=(1 / 3) \mu+(1 / 2)), \quad\left(\pi_{1}^{N}=(1 / 36)(3-2 \mu)^{2}\right)$, and $\left(\pi_{2}^{N}=(1 / 36)(3+2 \mu)^{2}\right)$, as in Lemma 1 . If firm 2 introduces a downward extension, we get the equations $v+\theta_{1} q_{2 l}-p_{2 l}+$ $\tau\left(1-\theta_{1}\right)=v+\theta_{1} q_{2 b}-p_{2 b} \quad$ and $v+\theta_{2} q_{2 b}-p_{2 b}=v+$ $\theta_{2} q_{1}-p_{1}$, so inserting $\theta_{1}=\left(p_{2 b}-p_{2 l}+\tau / \mu+\tau\right), \theta_{2}=p_{1}-$ $p_{2 b}$ into profit functions: $\left\{\begin{array}{l}\pi_{1}=\left(1-\theta_{2}\right)\left(p_{1}-c_{1}\right), \\ \pi_{2}=\left(\theta_{2}-\theta_{1}\right)\left(p_{2 b}-c_{2 b}\right)+\theta_{1}\left(p_{2 l}-c_{2 l}\right) .\end{array} \quad\right.$ Calculate the first-order derivative of profit functions with respect to $p_{1}$, $p_{2 b}$, and $p_{2 l}$, respectively, and we obtain 


$$
\begin{aligned}
& p_{1}^{D *}=\frac{1}{2} \mu^{2}+\frac{2}{3} \mu+1, \\
& p_{2 b}^{D *}=\frac{1}{2} \mu^{2}+\frac{1}{3} \mu+\frac{1}{2}, \\
& p_{2 l}^{D *}=\frac{1}{4} \mu^{2}+\frac{1}{3} \mu+\frac{1}{2} \tau+\frac{1}{2}, \\
& \theta_{1}^{D *}=\frac{\mu^{2}+2 \tau}{4(\mu+\tau)}, \\
& \theta_{2}^{D *}=\frac{1}{3} \mu+\frac{1}{2}, \\
& \pi_{1}^{D *}=\frac{1}{36}(3-2 \mu)^{2}, \\
& \pi_{2}^{D *}=\frac{9 \mu^{4}+16 \mu^{3}+(52 \tau+48) \mu^{2}+(48 \tau+36) \mu+36 \tau(\tau+1)}{144(\tau+\mu)} .
\end{aligned}
$$

If firm 2 introduces an upward extension, we get the equations $\quad\left(v+\theta_{1} q_{2 b}-p_{2 b}=v+\theta_{1} q_{2 h}-p_{2 h}+\tau\left[1-\left(\theta_{2}-\right.\right.\right.$ $\left.\left.\left.\theta_{1}\right)\right]\right)$ and $\left(v+\theta_{2} q_{2 h}-p_{2 h}+\tau\left[1-\left(\theta_{2}-\theta_{1}\right)\right]=v+\theta_{2} q_{1}-\right.$ $\left.p_{1}\right)$, so inserting $\theta_{1}=\left(\left(p_{2 h}-p_{2 b}-\tau\left(1-\theta_{2}\right)\right) / 1-\mu+\tau\right)$ and $\theta_{2}=\left(p_{1}-p_{2 h}-\tau\left(1+\theta_{1}\right) / \mu+\tau\right)$ into profit functions, we obtain $\left\{\begin{array}{l}\pi_{1}=\left(1-\theta_{2}\right)\left(p_{1}-c_{1}\right), \\ \pi_{2}=\left(\theta_{1}\right)\left(p_{2 b}-c_{2 b}\right)+\left(\theta_{2}-\theta_{1}\right)\left(p_{2 h}-c_{2 h}\right) .\end{array}\right.$

Calculate the first-order derivative of profits functions with respect to $p_{1}, p_{2 b}$, and $p_{2 h}$, respectively, and we obtain

$$
\begin{aligned}
p_{1}^{U *}= & 1+\frac{\mu\left(6 \mu^{2}+3 \tau \mu+2 \tau\right)}{6(\mu+\tau)}, \\
p_{2 b}^{U *}= & \frac{1}{2}+\frac{\mu\left(9 \mu^{2}+6 \tau \mu+2 \tau\right)}{12(\mu+\tau)}, \\
p_{2 h}^{U *}= & \frac{6 \tau^{2}+\left(15 \mu^{2}+8 \mu\right) \tau+18 \mu^{3}}{12(\mu+\tau)}+\frac{1}{2}, \\
\theta_{1}^{U *}= & \frac{9 \mu^{4}+(6 \tau-9) \mu^{3}-15 \tau \mu^{2}-8 \tau^{2} \mu}{12(\tau+\mu)\left(\mu^{2}-\mu-\tau\right)}, \\
\theta_{2}^{U *}= & \frac{3 \mu^{3}-(4 \tau+3) \mu-3 \tau}{6\left(\mu^{2}-\mu-\tau\right)}, \\
\pi_{1}^{U *}= & \frac{\left[-3 \mu^{3}+6 \mu^{2}+(4 \tau-3) \mu-3 \tau\right]^{2}}{36\left(\mu+\tau-\mu^{2}\right)(\tau+\mu)}, \\
\pi_{2}^{U *}= & \frac{144(\tau+\mu)\left(\mu^{2}-\mu-\tau\right)}{14}, \\
G= & 45 \mu^{6}-81 \mu^{5}+(72-93 \tau) \mu^{4}+180 \tau \mu^{3} \\
& +\left(80 \tau^{2}-96 \tau-36\right) \mu^{2}-\left(132 \tau^{2}+72 \tau\right) \mu-36 \tau^{2}(1+\tau) .
\end{aligned}
$$

The necessary condition is given by $\left(\mu^{2} / 2\right)<\tau<\tau^{m}=$ $\left(\left(-9 \mu^{2}-4 \mu+6+\sqrt{81 \mu^{4}-72 \mu^{3}-92 \mu^{2}+96 \mu+36}\right) / 12\right)$. Let $\pi_{2}^{U *}-\pi_{2}^{N}=\left(G /\left(144(\tau+\mu)\left(\mu^{2}-\mu-\tau\right)\right)\right)-(1 / 36)(3+2 \mu)^{2}$ $=0$, and we have a function of $\mu: F(\mu)$ and prove $\left(\mu^{2} / 2\right)<F(\mu)<\tau^{m}$. When $\tau>F(\mu), \pi_{2}^{U *}-\pi_{2}^{N}>0$. Similarly, let $\pi_{2}^{U *}-\pi_{2}^{D *}=0$, and we get a function of $\mu$ : $M(\mu)$. When $\tau>M(\mu), \pi_{2}^{U *}-\pi_{2}^{D *}>0$.

Proof of Proposition 6. If we relax the assumption of firm 2 quality, set $q_{2}=q>0$. As the analytic process above, we can obtain the results in Table 3 .

In addition, in the situation of no extensions, the necessary condition is $(0<q<(3 / 2))$. In the situation of the downward extension, the necessary condition is $\left(0<q<\left(\left(\mu\left[-3 \mu^{3}+(3-2 \tau) \mu^{2}+5 \tau \mu+4 \tau^{2}\right]\right) /(2(2 \tau+3 \mu)\right.\right.$ $\left.\left.\left.\left(-\mu^{2}+\mu+\tau\right)\right)\right)<(3 / 2)\right)$. In the situation of the upward extension, the necessary condition is $\left(0<q<\left(\left(2 \tau-\mu^{2}\right) / 2 \mu\right)\right)$ and $\tau>\left(\mu^{2} / 2\right)$.

Without unique preferences, $\pi_{1}^{D *}-\pi_{1}^{N}=$ $(\mu / 144)\left[20 q^{2}+(32-20 \mu) q+5 \mu^{2}-20 \mu-12\right]$. If $\quad(0<q<$ $(\mu / 2))$, we can get $\pi_{1}^{D *}-\pi_{1}^{N}<0$.

With unique preferences, $\pi_{1}^{D *}-\pi_{1}^{N}=(M /$ $\left.\left(144(\tau+\mu)\left(\mu^{2}-\mu-\tau\right)\right)\right)$ and $M=5 \mu^{6}-(20 q+25) \mu^{5}+$ $\left(20 q^{2}+52 q-29 \tau+8\right) \quad \mu^{4}+\left[-20 q^{2}-32 q+12-(60 q+\right.$ 92) $\tau] \mu^{3}-\left[20 q^{2}+72 \quad q-96 \tau+36\right] \tau \mu^{2}-(40 q+84) \tau^{2} \mu-$ $36 \tau^{3}$. Let $M=0$, and we obtain $\tau^{*}=F(\mu, q)$ (Expression is too complex to list). When $\tau>F(\mu, q), \pi_{1}^{D *}-\pi_{1}^{N}>0$.

Similarly, $\quad\left(\pi_{1}^{D *}-\pi_{1}^{U *}=\left(\mu / 36(\tau+\mu)\left(\mu^{2}-\mu-\tau\right)\right) N\right)$ and $\quad N=-5 \mu^{5}-(14 q+4) \mu^{4}+\left[-4 q^{2}+22 q+4 \tau+2\right] \mu^{3}+$ $\left[4 q^{2}-8 q+(42 q+14) \tau+3\right] \tau \mu^{2}+\left(4 q^{2}-36 q-4 \tau-9\right) \tau \mu-$ $(28 q+12) \tau^{2}$. Let $N=0$, and we get $\tau^{*}=N(\mu, q)=$ $(\mu / 8(7 q+\mu+3))\left[4 q^{2}+(42 \mu-36) q+4 \mu^{2}+14 \mu-9+\sqrt{B}\right]$ and $B=\left(164 q^{2}+120 q-36\right) \mu^{2}-\left(112 q^{2}+576 q^{2}+\right.$ $612 q+108) \mu+\quad\left(4 q^{2}+20 q+15\right)^{2}$. When $\tau>N(\mu, q)$, $\pi_{1}^{D *}-\pi_{1}^{U *}>0$.

Figure 11 shows the trend of $N(\mu, q)$, and the feasible space of introducing an upward extension is larger with 
Table 3: Equilibrium outcomes when the high-quality firm expands the product line.

\begin{tabular}{|c|c|c|}
\hline Cases & Variables & Values \\
\hline No extensions & $\begin{array}{l}\text { Prices } \\
\text { Segments } \\
\text { Profits }\end{array}$ & $\begin{array}{c}\left(p_{1 b}^{N}=(1 / 2) q^{2}+(2 / 3) q+1\right),\left(p_{2}^{N}=(1 / 2) q^{2}+(1 / 3) q+(1 / 2)\right) \\
(\bar{\theta}=(1 / 3) q+(1 / 2)) \\
\left(\pi_{1}^{N}=(1 / 36)(3-2 q)^{2}\right) ;\left(\pi_{2}^{N}=(1 / 36)(3+2 q)^{2}\right)\end{array}$ \\
\hline $\begin{array}{l}\text { Downward } \\
\text { extension }\end{array}$ & $\begin{array}{c}\text { Prices } \\
\text { Segments } \\
\text { Profits }\end{array}$ & $\begin{array}{c}p_{1 b}^{D *}=\left(\left(\mu^{3}-(2 q+4) \mu^{2}+\left(6 q^{2}+8 q-2 \tau+12\right) \mu+\left(6 q^{2}+8 q+12\right) \tau\right) / 12(\tau+\mu)\right) ; \\
p_{1 l}^{D *}=\left(\left(4 \mu^{3}-(8 q+16-3 \tau) \mu^{2}+\left(6 q^{2}+8 q-8 \tau-6 q \tau+12\right) \mu+\left(6 q^{2}+8 q+6 \tau+12\right) \tau\right) / 12(\tau+\mu)\right) ; \\
p_{2}^{D *}=\left(\left(\mu^{3}-(2 q+4) \mu^{2}+\left(3 q^{2}+2 q-2 \tau+3\right) \mu+\left(3 q^{2}+2 q+3\right) \tau\right) / 6(\tau+\mu)\right) \\
\theta_{1}^{U *}=\left(\left(-\mu^{3}+(2 q+4) \mu^{2}-(2 q-2 \tau+3) \mu-(2 q+3) \tau\right) / 6\left(\mu^{2}-\mu-\tau\right)\right) ; \theta_{2}^{D^{*}}=\left(F^{1} / 12\left(\mu^{2}-\mu-\tau\right)(\tau+\mu)\right) \\
\pi_{1}^{D *}=\left(G^{2} /\left(144(\tau+\mu)\left(\mu^{2}-\mu-\tau\right)\right)\right) ; \\
\pi_{2}^{D *}=\left(\left[\mu^{3}-(2 q+4) \mu^{2}+(2 q-2 \tau+3) \mu+(2 q+3) \tau\right]^{2} /\left(36\left(\mu+\tau-\mu^{2}\right)(\tau+\mu)\right)\right)\end{array}$ \\
\hline $\begin{array}{c}\text { Upward } \\
\text { extension }\end{array}$ & $\begin{array}{l}\text { Prices } \\
\text { Segments } \\
\text { Profits }\end{array}$ & $\begin{array}{c}p_{1 b}^{U *}=(1 / 2) q^{2}+(2 / 3) q+1 ; p_{1 h}^{U *}=(1 / 2) q^{2}+(1 / 12)(6 \mu+8) q+(1 / 4) \mu^{2}+\mu+(1 / 2) \tau+1 \\
\left(p_{2}^{U *}=(1 / 2) q^{2}+(1 / 3) q+(1 / 2)\right) \\
\left(\theta_{1}^{U *}=(1 / 3) q+(1 / 2)\right) ; \theta_{2}^{U *}=\left(\left(\mu^{2}+(4+2 q) \mu+2 \tau\right) / 4(\mu+\tau)\right) \\
\pi_{1}^{U *}=\left(H^{3} / 144(\tau+\mu)\right) ;\left(\pi_{2}^{U *}=(1 / 36)(3+2 q)^{2}\right)\end{array}$ \\
\hline
\end{tabular}

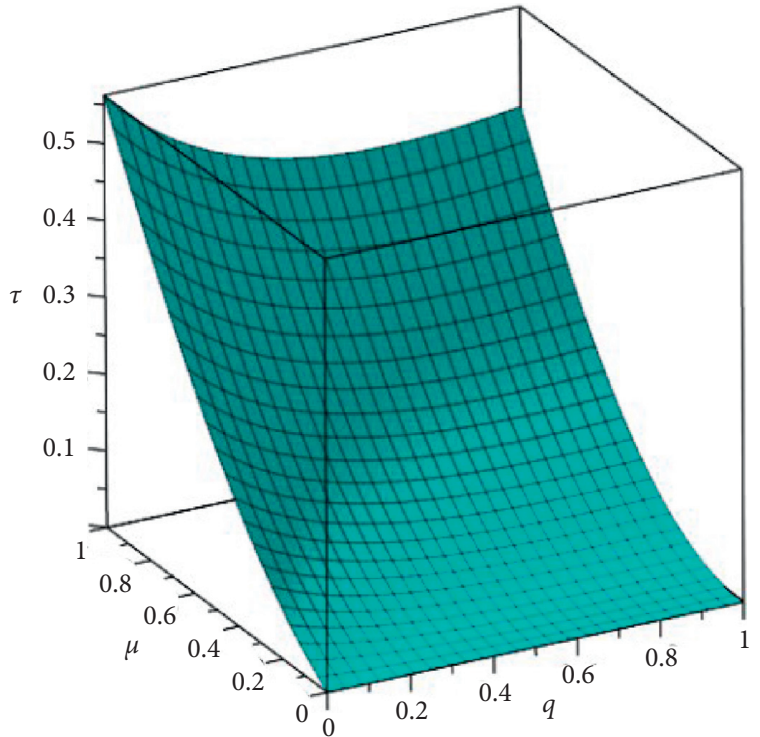

Figure 11: The changes of $N(\mu, q)$.

smaller unique preferences and bigger quality differentiation between the base product and extensions of the high-quality firm. An upward extension is more profitable with increasing quality of the low-quality firm's product. Otherwise, the high-quality firm will introduce a downward extension with customization technology.

(1) $F=-3 \mu^{4}+(6 q-2 \tau+15) \mu^{2}+(4 q \tau+17 \tau-6 q-$ 12) $\mu^{2}+\left(4 \tau^{2}-10 q \tau-24 \tau\right) \mu-4 \tau^{2}(q+3)$

(2) $G=-5 \mu^{6}+(20 q+25) \mu^{5}+\left(-20 q^{2}-52 q+29 \tau-\right.$ $8) \mu^{4}+\left[4 q^{2}+80 q-48-(60 q+92) \tau\right] \mu^{3}+\left[-56 \tau^{2}\right.$ $\left.+\left(4 q^{2}+120 q\right) \tau+(4 q-6)^{2}\right] \mu^{2}+[(40 q+84) \tau+$ $\left.2(4 q-6)^{2}\right] \tau \mu+\left[36 \tau+(4 q-6)^{2}\right] \tau^{2}$

(3) $H=9 \mu^{4}+36 q \mu^{3}+\left(36 q^{2}-36 \tau\right) \mu^{2}+[-72 q \tau+$ $\left.(4 q-6)^{2}\right] \mu+\left[36 \tau+(4 q-6)^{2}\right] \tau$

Proof of Proposition 7. When $\left(\tau_{1}<\tau<L(\mu) \tau_{m}\right)$, we know that $\pi_{1}^{U *}-\pi_{1}^{N}>0$ and $\pi_{1}^{D *}-\pi_{1}^{N}<0$ So, if $F<\pi_{1}^{U *}-\pi_{1}^{N}$, the high-quality firm tends to introduce an upward extension. Otherwise, it would make no extensions.

When $\quad\left(L(\mu) \leq \tau<\tau_{m}\right)$, we know that $\pi_{1}^{U *}-\pi_{1}^{N}>\pi_{1}^{D *}-\pi_{1}^{N}>0$. So, if $F<\pi_{1}^{U *}-\pi_{1}^{N}$, the highquality firm tends to introduce an upward extension. Otherwise, it would make no extensions.

When $\tau_{m} \leq \tau<\tau_{2}$, we know that $\pi_{1}^{D *}-$ $\pi_{1}^{N}>\pi_{1}^{U *}-\pi_{1}^{N}>0$. So, if $F<\pi_{1}^{D *}-\pi_{1}^{N}$, the high-quality firm tends to introduce a downward extension. Otherwise, it would make no extensions.

\section{Data Availability}

The data used to support the findings of this study are included within the article.

\section{Conflicts of Interest}

The authors declare that there are no conflicts of interest regarding the publication of this paper.

\section{Acknowledgments}

This work was supported by the Major Program of National Fund of Philosophy and Social Science of China (Grant no. 15ZDB150); MOE Layout Foundation of Humanities and Social Sciences (Grant no. 13YJA630078); National Natural Science Foundation of China (Grant nos. 71371151 and 71390330); and National Key Research and Development Program of China (Grant no. 2019YFB1704103).

\section{References}

[1] H. Wong and D. Lesmono, "On the evaluation of product customization strategies in a vertically differentiated market," International Journal of Production Economics, vol. 144, no. 1, pp. 105-117, 2013.

[2] E. Spaulding and C. Perry, Making it Personal: Rules for Success in Product Customization, Bain \& Company Publication, Atlanta, GA, USA, 2013.

[3] S. Hatton-Jones and M. Teah, "Case analysis of the do-ityourself industry," Asia Pacific Journal of Marketing and Logistics, vol. 27, no. 5, pp. 826-838, 2015. 
[4] T. T. Kelly, W. O. Bearden, and G. L. Hunter, "Consumers' need for uniqueness: scale development and validation," Journal of Consumer Research, vol. 28, no. 1, pp. 50-66, 2001.

[5] K. Kim, D. Chhajed, and Y. Liu, "Can commonality relieve cannibalization in product line design?" Marketing Science, vol. 32, no. 3, pp. 510-521, 2013.

[6] P. Desai, S. Kekre, S. Radhakrishnan, and K. Srinivasan, "Product differentiation and commonality in design: balancing revenue and cost drivers," Management Science, vol. 47 , no. 1 , pp. 37-51, 2002.

[7] V. Krishnan and S. Gupta, "Appropriateness and impact of platform-based product development," Management Science, vol. 47 , no. 1 , pp. 52-68, 2001.

[8] J. Bing, "On the profitability of firms in a differentiated industry," Marketing Science, vol. 25, no. 3, pp. 248-259, 2006.

[9] U. Lehmann-Grube, "Strategic choice of quality when quality is costly: the persistence of the high-quality advantage," The Rand Journal of Economics, vol. 28, no. 2, pp. 372-384, 1997.

[10] N. B. Syam and N. Kumar, "On customized goods, standard goods, and competition," Marketing Science, vol. 25, no. 5, pp. 525-537, 2006.

[11] N. B. Syam, R. Ruan, and J. D. Hess, "Customized products: a competitive analysis," Marketing Science, vol. 24, no. 4, pp. 569-584, 2005.

[12] Q. Yang, Z. Li, H. Jiao, Z. Zhang, W. Chang, and D. Wei, "Bayesian network approach to customer requirements to customized product model," Discrete Dynamics in Nature and Society, vol. 2019, Article ID 9687236, 16 pages, 2019.

[13] Z. Gu and G. K. Tayi, "Research note-investigating firm strategies on offering consumer-customizable products," Information Systems Research, vol. 26, no. 2, pp. 456-468, 2015.

[14] S. Ba and B. R. Nault, "Emergent themes in the interface between economics of information systems and management of technology," Production and Operations Management, vol. 26, no. 4, pp. 652-666, 2017.

[15] L. Xu, S. Lou, P. Xu, and G. Zhang, "Feedback control and parameter invasion for a discrete competitive lotka-volterra system," Discrete Dynamics in Nature and Society, vol. 2018, Article ID 3572094, 8 pages, 2018.

[16] W. J. Lane, "Product differentiation in a market with endogenous sequential entry," The Bell Journal of Economics, vol. 11, no. 1, pp. 237-260, 1980.

[17] J. P. Johnson and D. P. Myatt, "Multiproduct quality competition:fighting brands and product line pruning," American Economic Review, vol. 93, no. 3, pp. 748-774, 2003.

[18] P. S. Desai, "Quality segmentation in spatial markets: when does cannibalization affect product line design?" Marketing Science, vol. 20, no. 3, pp. 265-283, 2001.

[19] M. Mussa and S. Rosen, "Monopoly and product quality," Journal of Economic Theory, vol. 18, no. 2, pp. 301-317, 1978.

[20] K. S. Moorthy, "Market segmentation, self-selection, and product line design," Marketing Science, vol. 3, no. 4, pp. 288-307, 1984.

[21] K. S. Moorthy and I. P. L. Png, "Market segmentation, cannibalization, and the timing of product introductions," Management Science, vol. 38, no. 3, pp. 345-359, 1992.

[22] E. Biyalogorsky and O. Koenigsberg, "Ownership coordination in a channel: incentives, returns, and negotiations," Quantitative Marketing and Economics, vol. 8, no. 4, pp. 461-490, 2010.

[23] S. Bhattacharya, V. Krishnan, and V. Mahajan, "Operationalizing technology improvements in product development decision-making," European Journal of Operational Research, vol. 149, no. 1, pp. 102-130, 2003.
[24] A. Cheema and A. M. Kaikati, "The effect of need for uniqueness on word of mouth," Journal of Marketing Research, vol. 47, no. 3, pp. 553-563, 2010.

[25] W. Amaldoss and S. Jain, "Conspicuous consumption and sophisticated thinking," Management Science, vol. 51, no. 10, pp. 1449-1466, 2005.

[26] W. Amaldoss and S. Jain, "Pricing of conspicuous goods: a competitive analysis of social effects," Journal of Marketing Research, vol. 42, no. 1, pp. 30-42, 2005.

[27] V. V. Agrawal, S. Kavadias, and L. B. Toktay, "The limits of planned obsolescence for conspicuous durable goods," Manufacturing \& Service Operations Management, vol. 18, no. 2, pp. 216-226, 2016.

[28] R. S. Rao and R. Schaefer, "Conspicuous consumption and dynamic pricing," Marketing Science, vol. 32, no. 5, pp. 786-804, 2013.

[29] N. Xia and S. Rajagopalan, "Standard vs. custom products: variety, lead time, and price competition," Marketing Science, vol. 28 , no. 5, pp. 887-900, 2009.

[30] A. Alptekinoğlu and C. J. Corbett, "Mass customization vs. mass production: variety and price competition," Manufacturing \& Service Operations Management, vol. 10, no. 2, pp. 204-217, 2008.

[31] A. Basu and S. Bhaskaran, "An economic analysis of customer co-design," Information Systems Research, vol. 29, no. 4, pp. 1-18, 2018.

[32] K. J. Li, "Status goods and vertical line extensions," Production and Operations Management, vol. 28, no. 1, p. 103, 2019.

[33] F. Caldieraro, L.-J. Kao, and M. Cunha, "Harmful upward line extensions: can the launch of premium products result in competitive disadvantages?" Journal of Marketing, vol. 79, no. 6, pp. 50-70, 2015.

[34] N. Franke and M. Schreier, "Why customers value selfdesigned products: the importance of process effort and enjoyment*," Journal of Product Innovation Management, vol. 27, no. 7, p. 1020, 2010.

[35] N. Franke and M. Schreier, "Product uniqueness as a driver of customer utility in mass customization," Marketing Letters, vol. 19, no. 2, pp. 93-107, 2008.

[36] S. Y. Gao, W. S. Lim, and C. S. Tang, "Entry of copycats of luxury brands," Marketing Science, vol. 36, no. 2, p. 272, 2017. 